\title{
Optimum taxation of inheritances
}

by

Johann K. Brunner ${ }^{\star}$ and Susanne Pech

Working Paper No. 0806

April 2008

Revised version Mav 2010

Johannes Kepler University of Linz Department of Economics Altenberger Strasse 69 A-4040 Linz - Auhof, Austria www.econ.jku.at

*) johann.brunner@jku.at phone +43 (0)732 2468-8248, -9821 (fax) 


\title{
Optimum taxation of inheritances *)
}

\author{
Johann K. Brunner \\ Susanne Pech ${ }^{\dagger}$ \\ University of Linz ${ }^{\star}$ \\ University of Linz ${ }^{\star}$ \\ •) both: Department of Economics, Altenberger Straße 69, 4040 Linz, Austria. \\ Email-addresses: johann.brunner@jku.at, susanne.pech@jku.at.
}

May 2010

\begin{abstract}
Inheritances create a second distinguishing characteristic of individuals, in addition to earning abilities. We incorporate this fact into an optimum income taxation model with bequests motivated by joy of giving, and show that a tax on inherited wealth is equivalent to a tax on expenditures, i. e. to a uniform tax on consumption plus bequests. These taxes have a positive effect on intertemporal welfare of the inheriting and future generations if, on average, high-able individuals inherit more wealth than low-able. Welfare of the bequeathing generation is affected negatively by an inheritance tax but not by an expenditure tax.
\end{abstract}

JEL classification: $\mathrm{H} 21, \mathrm{H} 24$

Keywords: optimum taxation, inheritance taxation.

*) We are grateful to Josef Falkinger and Josef Zweimüller for helpful comments.

$\dagger$ Corresponding author. University of Linz, Department of Economics, Altenberger Straße 69, 4040 Linz, Austria. Tel. +43/732 2468-8593, Fax: +43/732 2468-9821, Email: susanne.pech@jku.at. 


\section{Introduction}

The tax on estates or inheritances has been a highly controversial issue for long. ${ }^{1}$ On the political level, opponents consider it morally inappropriate to use the moment of death as a cause for imposing a tax, and stress its negative economic consequences, in particular on capital accumulation and on family business. Supporters find these consequences exaggerated and claim that a tax on bequests is desirable for redistributive reasons, contributing to "equality of opportunity".

The intention of this paper is to propose an optimum-taxation model, which allows a discussion of the central question: is a shift from labor income taxation to a tax on intergenerational wealth transfers a desirable means of redistribution? To answer this question, we extend the standard optimum income taxation approach in the tradition of Mirrlees (1971) to a sequence of generations and introduce intergenerational wealth transfers. These transfers are assumed to be motivated by joy of giving (bequests as consumption, see, e.g., Cremer and Pestieau 2006): the amount left to the descendants has a positive effect on the parents' utility similar to the consumption of a good. ${ }^{2}$ Individuals differ in their earning abilities, inherited wealth increases their budget on top of their labor income; and they use their budget for consumption and bequests left to the next generation.

The essential point of our analysis is the following: inherited wealth creates a second distinguishing characteristic of individuals, in addition to earning abilities, and it is this fact which motivates the view that a tax on estates or inheritances enhances equality of opportunity. Therefore, the relevant task is to derive optimum-taxation results in a model which allows a simultaneous consideration of both the intragenerational heterogeneity in abilities and the dynamics of inequality arising from intergenerational wealth transfers.

\footnotetext{
Specifically in the USA, there has been a heated debate on the proposal to repeal the federal estate tax permanently. In 2006 it failed the required majority narrowly in the Senate, after the House of Representatives had voted overwhelmingly for the permanent repeal. Some countries like Sweden, Austria and Singapore have recently abolished taxation of inherited wealth. However, many other countries, in particular in Europe, still stick to their taxes on inheritance.

2 Another motive would be pure altruism, where the parents' utility function has utility of the descendants as an argument. This motive leading to dynastic preferences; bequest taxation in this framework was analyzed in Brunner and Pech (2010a). In the present work we do not intend to model redistribution between dynasties, but between individuals in each generation. We also leave out the strategic bequest motive as well as unintended bequests (for the latter, see Blumkin and Sadka 2003; they study estate taxation also in case of dynastic preferences).
} 
Typically former contributions discussing bequest taxation in an optimum-taxation framework have focused on the specifics of leaving bequests, as compared to other ways of spending the budget, that is, consumption of goods. Such an analysis, referring to a standard result in optimum-taxation theory (Atkinson and Stiglitz 1976, among others), leads to the question of whether preferences are separable between leisure and consumption plus bequests - then an income tax alone suffices, spending need not be taxed at all -, or whether leaving bequests represents a complement or a substitute to enjoying leisure. ${ }^{3} \mathrm{We}$ argue in the present paper that this is the inappropriate question, because the AtkinsonStiglitz result is derived for a model where individuals only differ in earning abilities. What matters is not that bequests represent a particular use of the budget, but the fact that they transmit inequality across generations.

There are some papers which do pay attention to the fact that inheritances create a second distinguishing characteristic, in addition to earning abilities. However, to our knowledge this literature does not provide a unified framework for an analysis of the role of bequest taxation within an optimum tax system. Cremer et al. (2001) resume the discussion of indirect taxes, given that individuals differ in endowments (inheritances) as well as abilities and that an optimum nonlinear tax on labor income is imposed. They assume, however, that inheritances are unobservable and concentrate on the structure of indirect tax rates. Similarly, Cremer et al. (2003) and Boadway et al. (2000) study the desirability of a tax on capital income as a surrogate for the taxation of inheritances, which are considered unobservable.

In contrast to these contributions, we study a comprehensive tax system where a nonlinear tax on labor income can be combined with taxes on inherited wealth and on expenditures. Therefore, we take all these variables as being observable (only abilities are unobservable). This is indeed the basis upon which real-world tax systems, including the tax on bequests, operate. In particular, notwithstanding the problems of observability, if we want to know whether the inheritance tax should be retained or abolished from a welfare-theoretic point of view, the analysis must be based on the assumption of observable initial wealth. ${ }^{4}$

3 See Gale and Slemrod (2001, p.33) and Kaplow (2001), as well as Blumkin and Sadka (2003) in the context of a dynastic model.

4 For an analysis of wealth taxation in the case of imperfect observability see Brunner et al. 2010. 
As a starting point we consider a static model with two types of individuals, who live for one period and hold exogenously given initial wealth, which together with labor income is used for the consumption of two goods. We discuss two tax systems: (i) an optimum tax on labor income combined with a proportional (direct) tax on initial wealth, and (ii) an optimum tax on labor income combined with a proportional (indirect) tax on all consumption expenditures. We show that these two tax systems are equivalent and that a tax on initial wealth or on consumption expenditures is desirable according to a utilitarian objective, if initial wealth increases with earning abilities. Both taxes allows further redistribution on top of what can be achieved through labor income taxation alone. Note that the wealth tax is lump-sum while the expenditure tax is not, but the distorting effect of the latter on labor supply can be offset by an adaptation of the labor income tax.

Then we turn to an analysis of the dynamic model, for which we choose the most parsimonious version appropriate for our purpose: there is a sequence of generations, where again each lives for one period. One of the consumption goods is now interpreted as bequests, which become the initial (= inherited) wealth of the following generation. ${ }^{5}$ When discussing the two equivalent ways of imposing a tax (either directly on inherited wealth or indirectly on expenditures, i.e. on consumption plus bequests), we now take into account that bequests left by some generation influence the welfare of future generations. It turns out, contrary to what one expects, that introducing dynamic effects does not change anything compared to the result of the static model: that inherited wealth increases with earning abilities remains the only decisive criterion for both ways of taxation. All other welfare effects - including those falling on later generations - associated with the introduction of the tax on inherited wealth (or on consumption plus bequests), are neutralized by the simultaneous adaptation of the optimum tax on labor income. Thus, we also find that the "double-counting" problem, which typically arises in models where bequests enter a social objective twice ${ }^{6}$, does not occur in our framework.

\footnotetext{
We assume that bequests are not productive but represent immediate consumption possibilities for the next generation. As individuals live for one period only, there is no other saving except for the purpose of leaving bequests, and a tax on wealth transfers is equivalent to a tax on capital income. Hence we need not introduce the latter.

6 Bequeathing causes two positive effects on the involved individuals (the donor enjoys giving, the beneficiary likes receiving), and the welfare of both appears in the social welfare function. This calls for a subsidy instead of a tax on bequests (see, among others, Farhi and Werning (2008) who show in a model with altruistic bequests that marginal tax rates are negative and increasing). Some authors discuss "laundering out" this double counting from the social welfare function, see, e. g., Cremer and Pestieau (2006).
} 
This result has to be modified somewhat if the first instrument (a tax directly imposed on inherited wealth) is applied and if one assumes that the bequeathing individuals care for bequests net of the inheritance tax falling on the heirs. Then collecting the tax in some period will have repercussions on the bequest decision of the previous generation. We show that the welfare effect depends on whether the revenues of the inheritance tax run in the budget of the bequeathing generation or into that of the inheriting generation. In the former case, the tax causes a deadweight loss due to the distortion of the bequest decision. In the latter case there is a stronger negative effect, because the parents experience the reduction of their net bequests, but do not recognize the redistribution of the tax revenues through diminished income tax obligations of the descendants. No repercussions on the previous generation arise if an expenditure tax instead of an inheritance tax is imposed, because with a joy-of-giving motive the bequest decision of the parents is not affected by a tax on expenditures of the descendants.

In a next step, we generalize the model to one with arbitrarily many types of individuals and with a stochastic relation between inherited wealth and earning abilities. Restricting the analysis to quasilinear preferences, we show that the results remain essentially unchanged, the crucial point for the desirability of a tax on inherited wealth (or on consumption plus bequests) being that expected inheritances increase with abilities. ${ }^{7}$

In the following Section 2 the model with two types of individuals is introduced and the results for the static as well as for the dynamic formulation are derived in turn. In Section 3 the model is generalized to more types and a stochastic relation between ability levels and inheritances. Section 4 provides concluding remarks.

\section{Two ways of taxing inherited wealth}

We begin this Section with an analysis of a static model, which will be extended to a dynamic framework with many generations in Subsection 2.2. The economy consists of two individuals $\mathrm{i}=\mathrm{L}, \mathrm{H}$, characterized by differing earning abilities $\omega_{\mathrm{L}}<\omega_{\mathrm{H}}$, and by

7 To our knowledge, there is no direct empirical evidence on this issue. However, it has been found that earnings are positively correlated with wealth (see, e.g., Díaz-Giménez et al. 2002 for the US economy, who find a positive correlation between earnings and wealth of 0.47 ). This can be seen as a partial support for a positive relation between inheritances and abilities, as wealth consists of inheritances to a substantial extent (for an overview see Kessler and Masson 1989). 
exogenous initial endowments of (inherited) wealth $\mathrm{e}_{\mathrm{i}}, \mathrm{i}=\mathrm{L}, \mathrm{H}$. The individuals live for one period. By supplying labor time $\mathrm{l}_{\mathrm{i}}$, each individual earns pre-tax income $z_{i}=\omega_{\mathrm{i}} \mathrm{l}_{\mathrm{i}}, \mathrm{i}=\mathrm{L}, \mathrm{H}$. After-tax income is denoted by $x_{i}$, which, together with initial wealth, is spent on general consumption $c_{i}$ and some specific good $b_{i}$. We call the latter good bequests to be consistent with the terminology later on, though - taken literally - it makes no sense to have bequests in a static model. The individuals have common preferences, described by the concave utility function $u(c, b, l)$, which is twice differentiable, with $\partial \mathrm{u} / \partial \mathrm{c}, \partial \mathrm{u} / \partial \mathrm{b}>0, \partial \mathrm{u} / \partial \mathrm{l}<0$.

\subsection{A basic equivalence}

The tax system consists of a tax on labor income, described implicitly by the function $\sigma$ : $\mathbb{R} \rightarrow \mathbb{R}$, which relates gross and net income: $x=\sigma(z)$, of a proportional tax $\tau_{\mathrm{e}}$ on initial wealth, and of proportional taxes $\tau_{\mathrm{c}}$ and $\tau_{\mathrm{b}}$ on consumption and bequests, resp. Assuming that the prices of consumption and bequests are one, the budget constraint of an individual $i$ reads:

$$
\left(1+\tau_{c}\right) c_{i}+\left(1+\tau_{b}\right) b_{i} \leq \sigma\left(z_{i}\right)+\left(1-\tau_{e}\right) e_{i}
$$

Obviously, $\tau_{\mathrm{e}}$ is a lump-sum tax in this case. It is well known that in the absence of initial wealth a tax system consisting of an income tax plus a uniform expenditure tax is equivalent to an income tax alone. This is no longer true, if there exist wealth endowments: then there is a case for a second tax instrument, in addition to the tax on labor income.

Lemma 1: A tax system $\left(\sigma, \tau_{\mathrm{e}}, \tau_{\mathrm{c}}, \tau_{\mathrm{b}}\right)$ is equivalent to a tax system $\left(\hat{\sigma}, \hat{\tau}_{\mathrm{e}}, \hat{\tau}_{\mathrm{c}}, \hat{\tau}_{\mathrm{b}}\right)$, where one of $\left(\hat{\tau}_{\mathrm{e}}, \hat{\tau}_{\mathrm{c}}, \hat{\tau}_{\mathrm{b}}\right)$ is zero. As a consequence, a tax system with a uniform expenditure $\operatorname{tax} \tau \equiv \tau_{\mathrm{c}}=\tau_{\mathrm{b}}$ is a equivalent to a system where $\hat{\tau}=0$ or $\hat{\tau}_{\mathrm{e}}=0$.

Proof: Follows immediately from appropriate manipulations of the budget constraint (1). Tax systems are equivalent if the associated budget sets are the same.

QED

Note that the switch to a tax system without a tax on initial wealth means that the income tax has to be reduced (divide (1) by $\left(1-\tau_{\mathrm{e}}\right)$, net income $\sigma(\mathrm{z})$ is increased), while the taxes on $c_{i}$ and $b_{i}$ have to be increased. Similarly, a switch such that expenditures are untaxed (assume $\tau=\tau_{\mathrm{c}}=\tau_{\mathrm{b}}$ and divide (1) by $(1+\tau)$ ) means an increase of the income tax and of the tax on initial wealth (if $\tau_{\mathrm{e}}<1$ ). 
Hence, a tax $\tau_{\mathrm{e}}$ on initial wealth is essentially the same as a uniform tax $\tau$ on expenditures for consumption and bequests (which in fact are a form of consumption), because the income tax can be adjusted accordingly. In particular, the uniform expenditure tax represents a kind of lump-sum tax in this framework, as does the tax on initial wealth, though expenditures are variable, while wealth is fixed.

This equivalence extends to the welfare effect of a marginal change of the tax system, which we discuss in an optimum income taxation framework. We introduce the indirect utility function

$$
v^{i}\left(x_{i}, z_{i}, e_{i}, \tau_{e}, \tau\right) \equiv \max \left\{u\left(c_{i}, b_{i}, z_{i} / \omega_{i}\right) \mid(1+\tau)\left(c_{i}+b_{i}\right) \leq x_{i}+\left(1-\tau_{e}\right) e_{i}\right\}
$$

As usual, we assume that the tax authority cannot tie a tax directly with individual abilities, because they are not observable, therefore it imposes an income tax as a second-best instrument. For the determination of the latter, we take some tax rate $\tau$ and/or $\tau_{\mathrm{e}}$ as fixed for the moment. In case that there are no restrictions on the functional form of the income tax, the appropriate way to determine the optimum nonlinear schedule is to maximize a social welfare function with respect to the individuals' income bundles $(\mathrm{x}, \mathrm{z})$, subject to the selfselection constraints and the resource constraints.

As is standard in optimum income taxation models, we assume that the condition of "agent monotonicity" (Mirrlees 1971, Seade 1982) holds. Define $\operatorname{MRS}_{z x}^{i} \equiv-\left(\partial v^{i} / \partial z_{i}\right) /\left(\partial v^{i} / \partial x_{i}\right)$, then for any given $e_{i}, \tau_{e}, \tau$ :

$$
\text { AM: } \operatorname{MRS}_{\mathrm{zx}}^{\mathrm{L}}>\mathrm{MRS}_{\mathrm{zx}}^{\mathrm{H}} \text { at any vector }(\mathrm{x}, \mathrm{z}) \text {. }
$$

This single-crossing condition guarantees that for any income tax function the high-able individual does not choose to earn less income than the low-able. ${ }^{8}$ We assume a utilitarian

\footnotetext{
It should be noted that in the presence of initial (non-human) endowments this assumption is more critical than in the standard model à la Mirrlees: if initial wealth of the high-able individual is sufficiently larger (thus, her marginal utility of income is sufficiently lower) than that of the low-able, the former might require a larger amount of net income as a compensation for her effort to earn one more unit of gross income, than what the latter requires (even though the high able needs less additional working time for this). Such a potential problem does not occur, if we work with quasilinear preferences, as we do in Section 3 .
} 
social welfare function with weights $f_{L}, f_{H}, f_{L} \geq f_{H}>0$, of the two individuals, then the objective is

$$
\max _{x_{i}, z_{i}} f_{L} v^{L}\left(x_{L}, z_{L}, e_{L}, \tau_{e}, \tau\right)+f_{H} v^{H}\left(x_{H}, z_{H}, e_{H}, \tau_{e}, \tau\right)
$$

The resource constraint reads

$$
\mathrm{x}_{\mathrm{L}}+\mathrm{x}_{\mathrm{H}} \leq \mathrm{z}_{\mathrm{L}}+\mathrm{z}_{\mathrm{H}}+\tau_{\mathrm{e}}\left(\mathrm{e}_{\mathrm{L}}+\mathrm{e}_{\mathrm{H}}\right)+\tau\left(\mathrm{c}_{\mathrm{L}}(\cdot)+\mathrm{b}_{\mathrm{L}}(\cdot)+\mathrm{c}_{\mathrm{H}}(\cdot)+\mathrm{b}_{\mathrm{H}}(\cdot)\right)-\mathrm{g}
$$

where $g$ denotes the resources required by the state. $c_{i}(\cdot), b_{i}(\cdot)$ are demand functions with the same arguments as $v^{i}(\cdot), i=L, H$. Concerning the self-selection constraints, we follow the standard assumption of a sufficient importance of the low-able individual in the objective function (2). That is, the social objective favors redistribution from the high- to the low-able individual and only the self-selection constraint of the high-able individual is binding in the optimum and needs to be considered:

$$
\mathrm{v}^{\mathrm{H}}\left(\mathrm{x}_{\mathrm{H}}, \mathrm{z}_{\mathrm{H}}, \mathrm{e}_{\mathrm{H}}, \tau_{\mathrm{e}}, \tau\right) \geq \mathrm{v}^{\mathrm{H}}\left(\mathrm{x}_{\mathrm{L}}, \mathrm{z}_{\mathrm{L}}, \mathrm{e}_{\mathrm{H}}, \tau_{\mathrm{e}}, \tau\right)
$$

Let, for given $\tau_{\mathrm{e}}, \tau$, the optimum value of the social welfare function (2) subject to the constraints (3) and (4) be denoted by $\mathrm{S}\left(\tau_{\mathrm{e}}, \tau\right)$, and let the Lagrange multiplier of the selfselection constraint (4) be denoted by $\mu . \mu$ is positive as a consequence of the above assumption that (4) is binding in the optimum. We use the notation $\partial \mathrm{v}^{\mathrm{H}}[\mathrm{L}] / \partial \mathrm{x}_{\mathrm{L}}>0$ to describe marginal utility of income of the high-able individual in case of mimicking. ${ }^{9}$

Theorem 1: The welfare effect of a marginal increase of $\tau_{\mathrm{e}}$ and $\tau$, resp., reads:
(a) $\frac{\partial \mathrm{S}}{\partial \tau_{\mathrm{e}}}=\mu \frac{\partial \mathrm{v}^{\mathrm{H}}[\mathrm{L}]}{\partial \mathrm{x}_{\mathrm{L}}}\left(\mathrm{e}_{\mathrm{H}}-\mathrm{e}_{\mathrm{L}}\right)$,
(b) $\frac{\partial \mathrm{S}}{\partial \tau}=\mu \frac{\partial \mathrm{v}^{\mathrm{H}}[\mathrm{L}]}{\partial \mathrm{x}_{\mathrm{L}}}\left(\mathrm{e}_{\mathrm{H}}-\mathrm{e}_{\mathrm{L}}\right) \frac{1-\tau_{\mathrm{e}}}{1+\tau}$.

Hence, $\partial \mathrm{S} / \partial \tau=\left(\partial \mathrm{S} / \partial \tau_{\mathrm{e}}\right)\left(1-\tau_{\mathrm{e}}\right) /(1+\tau)$ and both taxes increase social welfare, if the initial wealth of the high-able individual is larger than that of the low-able.

\footnotetext{
9 Mimicking refers to a situation where the high-able individual opts for the (x,z)-bundle designed for the low-able.
} 
Proof: see Appendix.

Given a larger wealth of the high-able individuals, the social objective calls for further redistribution than what is possible through an income tax alone. Such an additional redistribution can equivalently be achieved by a tax on initial wealth or on expenditures. In particular, it turns out that the justification for (uniform) indirect taxation is uniquely linked to the existence of differing wealth endowments: given these, the expenditure tax combined with an optimum income tax is indeed a lump-sum tax, being equivalent to the tax on initial wealth.

The positive effect on welfare comes from a relaxation of the self-selection constraint induced by an increase of $\tau_{\mathrm{e}}$ (or $\tau$ ). The intuition can be explained as follows: assume, as a first step, that after an increase of $\tau_{\mathrm{e}}$ by $\Delta \tau_{\mathrm{e}}$, each individual $\mathrm{i}$ is just compensated through an increase of net labor income $\mathrm{x}_{\mathrm{i}}$ by $\Delta \tau_{\mathrm{e}} \mathrm{e}_{\mathrm{i}}$. If $\mathrm{e}_{\mathrm{H}}>\mathrm{e}_{\mathrm{L}}$, the high-able individual experiences a larger increase of the net labor income than the less able which makes mimicking less attractive and gives slack to the self-selection constraint. As a consequence, in a second step additional redistribution from the high- to the low-able individuals becomes possible, which increases social welfare. ${ }^{10}$

One may object to our model that assuming a fixed relation between (unobservable) abilities and (observable) initial wealth (or expenditures) makes an income tax not a reasonable instrument from the beginning. Namely, the tax authority can use information on initial wealth (or on expenditures) to identify individuals, and then impose a tax on abilities directly, which is first-best. In reality, however, such a method of identification is not employed, and the main reason seems to be that initial wealth (or expenditures) is not a precise indicator for earning abilities. By incorporating this idea in our model we will show in Section 3 that an accordingly modified version of Theorem 1 also holds when initial wealth is stochastic.

10 In this paper we are only interested in the marginal effect of introducing $\tau$ or $\tau_{\mathrm{e}}$, which is positive as long as the social objective favors redistribution. To determine optimum rates, a counteracting effect has to be introduced, see Brunner et. al. 2010. 


\subsection{Taxation of inheritances in a dynamic economy}

As a next step we formulate a simple intertemporal model within which we discuss the optimum taxation of inheritance. We assume that the (static) two-person economy described above represents the situation in some single period $t$, and we take into account that taxes affect the welfare of future and prior generations.

We follow the idea of the foregoing Subsection that receiving inheritances creates a second distinguishing characteristic of the individuals, in addition to their earning abilities. In order to account for this, two possible instruments can be applied in some period t: (1) levying a $\operatorname{tax} \tau_{\text {et }}$ on inherited wealth $\mathrm{e}_{\mathrm{it}}$, to reduce inequality within the receiving generation $\mathrm{t}$ or (2) using a tax on "full" expenditures of generation $t$ (that is, in our terminology, a uniform tax $\tau_{t}$ on their consumption $c_{i t}$ plus bequests $b_{i t}$ ) as a surrogate taxation of inherited wealth $e_{i t}$.

In a static framework, these two instruments proved equivalent (and lump-sum). We now ask what can be said in an intertemporal setting, that is, when effects on future generations are taken into account. Let a series of arbitrary tax rates $\tau_{\mathrm{es}}, \tau_{\mathrm{s}}$ for the periods $\mathrm{s} \geq \mathrm{t}$, be given (possibly zero). In some period t, the government imposes an optimum income tax and considers a change of $\tau_{\mathrm{et}}, \tau_{\mathrm{t}}$. The revenues from $\tau_{\mathrm{et}}, \tau_{\mathrm{t}}$ run into the budget of this generation $\mathrm{t}$ and are redistributed through a reduced need for labor-income tax revenues.

\section{Effects on future generations}

We work with the indirect utility functions as before, now being defined as

$$
v_{t}^{i}\left(x_{i t}, z_{i t}, e_{i t}, \tau_{e t}, \tau_{t}\right) \equiv \max \left\{u\left(c_{i t}, b_{i t}, z_{i t} / \omega_{i t}\right) \mid\left(1+\tau_{t}\right)\left(c_{i t}+b_{i t}\right) \leq x_{i t}+\left(1-\tau_{\text {et }}\right) e_{i t}\right\} .
$$

Inherited wealth $e_{i t}$ of an individual $i$ of generation $t$ is exogenous. It arises as a result of some allocation of aggregate bequests $b_{\mathrm{Lt}-1}+b_{\mathrm{Ht}-1}$ left by the previous generation to the individuals of generation t. For the analysis of this Section, the rules guiding this allocation need not be specified.

On the other hand, the bequests $b_{i t}(\cdot)$ left by generation $t$ represent initial wealth for the individuals of the next generation $\mathrm{t}+1$ and enter their utility. Moreover, they also influence bequests left by generation $\mathrm{t}+1$ and, by this, utility of generation $\mathrm{t}+2$, and so on. We take 
account of all these effects through a very general formulation: we assume that (discounted) welfare of all future generations from $\mathrm{t}+1$ onwards can be described by some general (intertemporal) social welfare function $\mathrm{W}\left(\mathrm{b}_{\mathrm{Lt}}, \mathrm{b}_{\mathrm{Ht}}\right)$, which depends on the bequests left to generation $\mathrm{t}+1 .{ }^{11}$ In order to determine the tax rates in period $\mathrm{t}$, the planner must take care of how the tax rates influence future welfare, and this happens only via bequests of generation $\mathrm{t}$ in our model. Thus, $\mathrm{W}$ must be known to the planner, but it can be any suitable function.

Then the objective function of the planner to determine the optimum nonlinear income tax in period $t$ reads

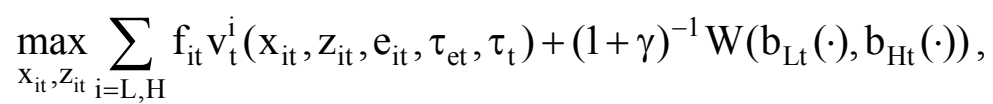

where $\gamma>0$ represents the planner's one-period discount rate. (6) is to be maximized subject to the resource constraint

$$
\mathrm{x}_{\mathrm{Lt}}+\mathrm{x}_{\mathrm{Ht}} \leq \mathrm{z}_{\mathrm{Lt}}+\mathrm{z}_{\mathrm{Ht}}+\tau_{\mathrm{et}}\left(\mathrm{e}_{\mathrm{Lt}}+\mathrm{e}_{\mathrm{Ht}}\right)+\tau_{\mathrm{t}}\left(\mathrm{c}_{\mathrm{Lt}}(\cdot)+\mathrm{b}_{\mathrm{Lt}}(\cdot)+\mathrm{c}_{\mathrm{Ht}}(\cdot)+\mathrm{b}_{\mathrm{Ht}}(\cdot)\right)-\mathrm{g}_{\mathrm{t}}
$$

and to the self-selection constraint

$$
\mathrm{v}_{\mathrm{t}}^{\mathrm{H}}\left(\mathrm{x}_{\mathrm{Ht}}, \mathrm{z}_{\mathrm{Ht}}, \mathrm{e}_{\mathrm{Ht}}, \tau_{\mathrm{et}}, \tau_{\mathrm{t}}\right) \geq \mathrm{v}_{\mathrm{t}}^{\mathrm{H}}\left(\mathrm{x}_{\mathrm{Lt}}, \mathrm{z}_{\mathrm{Lt}}, \mathrm{e}_{\mathrm{Ht}}, \tau_{\mathrm{et}}, \tau_{\mathrm{t}}\right) .
$$

Note again that $b_{\mathrm{Lt}}, \mathrm{b}_{\mathrm{Ht}}$, influenced by the income tax in period $\mathrm{t}$ and by the taxes $\tau_{\mathrm{et}}, \tau_{\mathrm{t}}$, enter welfare $\mathrm{W}$ of future generations. ${ }^{12} \mathrm{We}$ find the surprising result that this effect plays no role for the desirability of $\tau_{\mathrm{et}}, \tau_{\mathrm{t}}$. Let $\mathrm{S}^{\mathrm{d}}\left(\tau_{\mathrm{et}}, \tau_{\mathrm{t}}\right)$ denote the optimum value of the maximization of

11 As mentioned in the Introduction, we assume a zero rate of return. However, even if there were a positive rate of return on (bequeathed) capital, its welfare effect would be included in $\mathrm{W}$, and our results would remain unchanged.

12 To give a simple example for $\mathrm{W}$ : assume that all later generations consist of the two types of individuals with ability level $\omega_{\mathrm{Ls}}, \omega_{\mathrm{Hs}}$ and in each period all bequests left by type $\mathrm{L}(\mathrm{H})$ go to type $\mathrm{L}(\mathrm{H})$ of the next generation $\left(\mathrm{e}_{\mathrm{is}}=\mathrm{b}_{\mathrm{is}-1}\right)$. We define $\mathrm{W}\left(\mathrm{b}_{\mathrm{Lt}}, \mathrm{b}_{\mathrm{Ht}}\right)$ as the maximum (discounted) future welfare, from $\mathrm{t}+1$ onwards, for given $b_{\mathrm{Lt}}, \mathrm{b}_{\mathrm{H}}$, if an optimum nonlinear income tax is imposed in each period, i.e.,

$$
\mathrm{W}\left(\mathrm{b}_{\mathrm{Lt}}, \mathrm{b}_{\mathrm{Ht}}\right) \equiv \max _{\mathrm{x}_{\mathrm{is}}, \mathrm{z}_{\mathrm{is}}} \sum_{\mathrm{s}=\mathrm{t}+1}^{\infty}(1+\gamma)^{\mathrm{t}+1-\mathrm{s}} \sum_{\mathrm{i}=\mathrm{L}, \mathrm{H}} \mathrm{f}_{\mathrm{is}} \mathrm{v}_{\mathrm{s}}^{\mathrm{i}}(\cdot),
$$

subject to the resource and the self-selection constraints $(7)$ and $(8)$, for every period $s=t+1, \ldots, \infty$. Note that bequests $b_{i t}=e_{i t+1}$ of generation $t$ enter $v_{t+1}^{i}(\cdot)$. 
(6), subject to (7) and (8), and $\mu^{\mathrm{d}}$ the Lagrange multiplier corresponding to the selfselection constraint (8):

Theorem 2: In a dynamic model, the welfare effect of a marginal increase of $\tau_{\text {et }}$ and $\tau_{\text {t, }}$ resp., in some period $t$, reads:

(a) $\frac{\partial \mathrm{S}^{\mathrm{d}}}{\partial \tau_{\mathrm{et}}}=\mu^{\mathrm{d}} \frac{\partial \mathrm{v}_{\mathrm{t}}^{\mathrm{H}}[\mathrm{L}]}{\partial \mathrm{x}_{\mathrm{Lt}}}\left(\mathrm{e}_{\mathrm{Ht}}-\mathrm{e}_{\mathrm{Lt}}\right)$,

(b) $\frac{\partial \mathrm{S}^{\mathrm{d}}}{\partial \tau_{\mathrm{t}}}=\mu^{\mathrm{d}} \frac{\partial \mathrm{v}_{\mathrm{t}}^{\mathrm{H}}[\mathrm{L}]}{\partial \mathrm{x}_{\mathrm{Lt}}}\left(\mathrm{e}_{\mathrm{Ht}}-\mathrm{e}_{\mathrm{Lt}}\right) \frac{1-\tau_{\mathrm{et}}}{1+\tau_{\mathrm{t}}}$.

Hence, as in the static model, both taxes increase welfare, if the inheritance received by the high-able individual is larger than that received by the low-able.

Proof: see Appendix.

Thus, the dynamic character does not change anything regarding the desirability of a tax on inherited wealth or on full expenditures (i.e. on consumption plus bequests). Though the tax on inherited wealth (or full expenditure) affects the amount of bequests left to the next generation, the same condition as in the static case applies, contrary to the intuition. The reason is the simultaneous adaptation of the optimum non-linear income tax, as can be seen from an inspection of the proof of Theorem 2. Indeed, an increase in $\tau_{\mathrm{et}}$ or $\tau_{\mathrm{t}}$ allows an increase in net income from labor which can, for each individual, be designed in such a way that all other welfare consequences of the increase of $\tau_{\text {et }}$ (or $\tau_{\mathrm{t}}$ ), in particular, the consequences for the subsequent generations via bequests, cancel out, except the one appearing in Theorem 2(a). The latter effect, which operates via a change of the selfselection constraint, is positive, if the high-able individual also has a higher wealth endowment, as discussed earlier.

This result may be interpreted as a rationale for the common idea that inheritance taxation serves the target of equality of opportunity. Its proponents implicitly assume that the group with the higher earning abilities also has higher inherited wealth. In the political decision it is also frequently taken for granted that taxation of bequests via an estate tax is an appropriate instrument for redistribution. However, as shown later on (Theorem 4), an 
estate tax alone leads to a distortion of the bequest decision, which is avoided if all expenditures, that is, consumption plus bequests, are taxed at a uniform rate.

A particularly interesting aspect of this cancelling out of all other welfare effects is that obviously the value of the social discount rate $\gamma$ - the weight of future generations - plays no direct role for the desirability of $\tau_{\text {et }}$ or $\tau_{t}$ (it influences the magnitude of the Lagrange multiplier $\mu^{\mathrm{d}}$ ). Moreover, as mentioned in the Introduction, our result shows that the wellknown "double-counting" of bequests, which in standard models causes a counter effect against the introduction of an estate or inheritance tax (and in fact calls for a subsidy), can be ignored as well. The point is again that in an appropriate formulation it is not the specific use of the budget for leaving a bequest which is taxed, but the initial wealth.

\section{Repercussions on the previous generation}

Up to now we have considered inherited wealth of generation $t$ as exogenously given. That is, we have assumed that, when the inheritance and/or full expenditure tax is increased or introduced in period $t$, the bequest decisions of the parent generation $t-1$ are already made. Then Theorem 2 describes the effect of these taxes on the present and future generation and obviously the same logic applies, if in period $\mathrm{t}+1$ the taxes $\tau_{\mathrm{et}+1}$ and/or $\tau_{\mathrm{t}+1}$ are introduced, unexpected by the previous generation $\mathrm{t}$.

As a further step of our analysis, we now ask whether something changes, if the increase or introduction of the inheritance and the full expenditure tax, resp., is anticipated by the bequeathing individuals in the previous period. To model this situation we assume that the taxes for both periods $t$ and $t+1$ are introduced (or increased) simultaneously. How does this affect the bequest behavior of the latter and what are the welfare consequences of the taxes in this case?

The answer to this question follows from the bequest motive in our model: bequests are regarded as some form of consumption; it is the amount left to the descendant, which per-se provides utility to the bequeathing individual. Thus, concerning the full expenditure tax, we can state as a first result that the introduction (or increase) of $\tau_{t+1}$, announced already in period t, does not change anything with the above analysis. The formula of Theorem 2(b), which describes the effect of $\tau_{t}$, applies - with index $t+1$ - in just the same way for the 
effect of $\tau_{t+1}$. The reason is that the full expenditure tax in period $t+1$ does, by definition, not change the value of the bequest $b_{i t}$ for the bequeathing individual $i$ of generation $t$, and does, therefore, not influence her bequest decision.

But the situation may be different when it comes to the direct tax on inherited wealth. Taking the bequest-as-consumption model literally, one might again argue that the anticipation of $\tau_{\mathrm{et}+1}$ by generation $\mathrm{t}$ does not change anything with the formula of Theorem 2(a), because individuals simply care for what they leave as (gross) bequests to their descendants. On the other hand, however, it seems reasonable to model the bequeathing generation $t$ as caring for net bequests, then $b_{i t}^{\text {net }} \equiv b_{i t}\left(1-\tau_{\text {et }+1}\right)$, instead of gross bequests $\mathrm{b}_{\mathrm{it}}{ }^{13}$ appears in her utility function. Such a formulation means that bequeathing individuals only pay attention to the after-tax amount going directly to the descendants, but they ignore the revenues raised by $\tau_{\mathrm{et}+1}$, though these run into the public budget of the descendants' generation and reduce their income tax burden.

With this formulation, the introduction (or increase) of an inheritance tax $\tau_{\mathrm{et}+1}$ causes a negative effect on the bequest decision of the previous generation $t$, which has not been considered so far. To analyze this effect in a model where taxes for the period $t$ and $t+1$ are fixed simultaneously in t, we extend the problem (6) - (8) by adding $\tau_{\mathrm{et}+1}$ as an argument of $v_{t}^{i}, c_{i t}$ and $b_{i t}$ (see (A12) in the Appendix). Moreover, in order to see the consequences in detail, we write welfare of generation $\mathrm{t}+1$ explicitly in the social objective and assume that the general welfare function $\mathrm{W}\left(\mathrm{b}_{\mathrm{Lt}+1}(\cdot), \mathrm{b}_{\mathrm{Ht}+1}(\cdot)\right)$ describes (discounted) social welfare from generation $\mathrm{t}+2$ onward. Thus, the objective function to determine the optimum bundles for the periods $t$ and $t+1$, for any given tax rates $\tau_{\mathrm{et}}, \tau_{\mathrm{t}}, \tau_{\mathrm{et}+1}, \tau_{\mathrm{t}+1}$ reads (instead of (6)):

$$
\max _{\mathrm{x}_{\mathrm{it}}, \mathrm{x}_{\mathrm{it}+1}, \mathrm{z}_{\mathrm{it}}, \mathrm{z}_{\mathrm{it}+1}} \sum_{\mathrm{i}=\mathrm{L}, \mathrm{H}} \mathrm{f}_{\mathrm{it}} \mathrm{v}_{\mathrm{t}}^{\mathrm{i}}(\cdot)+(1+\gamma)^{-1} \sum_{\mathrm{i}=\mathrm{L}, \mathrm{H}} \mathrm{f}_{\mathrm{it}+1} \mathrm{v}_{\mathrm{t}+1}^{\mathrm{i}}(\cdot)+(1+\gamma)^{-2} \mathrm{~W}\left(\mathrm{~b}_{\mathrm{Lt}+1}, \mathrm{~b}_{\mathrm{Ht}+1}\right)
$$

Further, a resource and a self-selection constraint for period $\mathrm{t}+1$ have to be added (see (A13) - (A16) in the Appendix).

13 Note that we use the expression "gross bequests" for $b_{\text {it }}$ from the viewpoint of the receiving generation $t+1$, i.e. only in reference to the inheritance tax $\tau_{\mathrm{et}+1}$. For the bequeathing generation $t$, however, $b_{\mathrm{it}}$ is pretax, if the full expenditure tax $\tau_{\mathrm{t}}$ exists as well. 
Obviously, bequests $b_{\text {it }}$ left by generation $t$ (being influenced by $\tau_{\text {et }+1}$ ) represent inheritances $\mathrm{e}_{i t+1}$ of generation $\mathrm{t}+1$. We still need not specify the precise rule of how the latter are allocated to the individuals, except that $\left(\mathrm{e}_{\mathrm{Lt}+1}+\mathrm{e}_{\mathrm{Ht}+1}\right)\left(1-\tau_{\mathrm{et}+1}\right)=\mathrm{b}_{\mathrm{Lt}}^{\text {net }}+\mathrm{b}_{\mathrm{Ht}}^{\text {net }}$ must hold. (A special case would be $\left.e_{i t+1}\left(1-\tau_{\mathrm{et}+1}\right)=b_{i t}^{\text {net }}, i=L, H\right)$. In order that the positive effect on the self-selection constraint occurs, as known from above, $\mathrm{e}_{\mathrm{Ht}+1}>\mathrm{e}_{\mathrm{Lt}+1}$ must be fulfilled.

Let $\tilde{S}^{\mathrm{d}}\left(\tau_{\mathrm{et}}, \tau_{\mathrm{t}}, \tau_{\mathrm{et}+1}, \tau_{\mathrm{t}+1}\right)$ denote the optimum value function of the extended problem and $\tilde{\mu}_{\mathrm{t}}^{\mathrm{d}}, \tilde{\mu}_{\mathrm{t}+1}^{\mathrm{d}}, \tilde{\lambda}_{\mathrm{t}+1}^{\mathrm{d}}$ the Lagrange multipliers corresponding to the self-selection constraints (in periods $t$ and $t+1$ ) and to the resource constraint in $t+1$, resp. We find by differentiation and manipulation of the Lagrangian function:

Theorem 3: In a dynamic model, where individuals care for net bequests, the welfare effect of a marginal increase of $\tau_{\mathrm{et}+1}$ and $\tau_{\mathrm{t}+1}$, resp., announced in period $\mathrm{t}$ already, reads:

$$
\begin{aligned}
& \text { (a) } \frac{\partial \tilde{\mathrm{S}}^{\mathrm{d}}}{\partial \tau_{\mathrm{et}+1}}=\frac{1+\tau_{\mathrm{t}}}{\left(1-\tau_{\mathrm{et}+1}\right)^{2}}\left[\sum_{\mathrm{i}=\mathrm{L}, \mathrm{H}}-\mathrm{f}_{\mathrm{it}} \mathrm{b}_{\mathrm{it}}^{\text {net }} \frac{\partial \mathrm{v}_{\mathrm{t}}^{\mathrm{i}}}{\partial \mathrm{x}_{\mathrm{it}}}-\tilde{\mu}_{\mathrm{t}}^{\mathrm{d}}\left(\mathrm{b}_{\mathrm{Ht}}^{\text {net }} \frac{\partial \mathrm{v}_{\mathrm{t}}^{\mathrm{H}}}{\partial \mathrm{x}_{\mathrm{Ht}}}-\mathrm{b}_{\mathrm{Ht}}^{\mathrm{net}}[\mathrm{L}] \frac{\partial \mathrm{v}_{\mathrm{t}}^{\mathrm{H}}[\mathrm{L}]}{\partial \mathrm{x}_{\mathrm{Lt}}}\right)\right]+ \\
& +\tilde{\mu}_{\mathrm{t}+1}^{\mathrm{d}} \frac{\partial \mathrm{v}_{\mathrm{t}+1}^{\mathrm{H}}[\mathrm{L}]}{\partial \mathrm{x}_{\mathrm{Lt}+1}}\left[\left(\mathrm{e}_{\mathrm{Ht}+1}-\mathrm{e}_{\mathrm{Lt}+1}\right)-\left(1-\tau_{\mathrm{et}+1}\right)\left(\frac{\partial \mathrm{e}_{\mathrm{Ht}+1}}{\partial \tau_{\mathrm{et}+1}}-\frac{\partial \mathrm{e}_{\mathrm{Lt}+1}}{\partial \tau_{\mathrm{et}+1}}\right)\right]+\tilde{\lambda}_{\mathrm{t}+1}^{\mathrm{d}} \sum_{\mathrm{i}=\mathrm{L}, \mathrm{H}} \frac{\partial \mathrm{e}_{\mathrm{it}+1}}{\partial \tau_{\mathrm{et}+1}}, \\
& \text { (b) } \frac{\partial \tilde{\mathrm{S}}^{\mathrm{d}}}{\partial \tau_{\mathrm{t}+1}}=\tilde{\mu}_{\mathrm{t}+1}^{\mathrm{d}} \frac{\partial \mathrm{v}_{\mathrm{t}+1}^{\mathrm{H}}[\mathrm{L}]}{\partial \mathrm{x}_{\mathrm{Lt}+1}}\left(\mathrm{e}_{\mathrm{Ht}+1}-\mathrm{e}_{\mathrm{Lt}+1}\right) \frac{1-\tau_{\mathrm{et}+1}}{1+\tau_{\mathrm{t}+1}} \text {. }
\end{aligned}
$$

Proof: see Appendix.

It turns out that the welfare effect of the inheritance tax is more complex in this case (Compare the RHS of Theorem 3a with the RHS of Theorem 2a, where the index $t$ is replaced by $\mathrm{t}+1$ ). Still, the remarkable property that all welfare effects for later generations cancel out, arises in this context as well: on the right-hand side of Theorem 3(a) effects on generations $\mathrm{t}+2$ and later do not appear.

The expression in the first square brackets in (a) shows us how the previous, bequeathing generation $\mathrm{t}$ is affected. As can be seen from the first term (it is, by Roy's Lemma equivalent to $\mathrm{f}_{\mathrm{it}} \partial \mathrm{v}_{\mathrm{t}}^{\mathrm{i}} / \partial \tau_{\mathrm{et}+1}$ ), the increase of a tax $\tau_{\mathrm{et}+1}$ on inherited wealth in period $\mathrm{t}+1$ has a direct negative effect on welfare of the parent generation, which anticipates the tax. This 
is a result of double-counting in the social welfare function: in the present model the inheritance tax diminishes welfare of two generations, viz. $t$ and $t+1$, while the revenues from the tax and their redistribution to the individuals have a positive impact only on generation $t+1$. The second term (multiplier $\tilde{\mu}_{t}^{d}$ ) shows that the increase of $\tau_{\text {et+1 }}$ also affects the self-selection constraint of generation $t$; its sign is undetermined for arbitrary preferences $^{14}$. (Clearly, $\tau_{\mathrm{et}+1}$ does not change the available resources in period $t$, therefore the resource constraint of this period is unaffected.)

The remaining expressions on the right-hand side of Theorem 3(a) describe the welfare consequences of $\tau_{\mathrm{et}+1}$ on the descendant generation $\mathrm{t}+1$. There is the effect of $\tau_{\mathrm{et}+1}$ on the self-selection constraint (multiplier $\tilde{\mu}_{\mathrm{t}+1}^{\mathrm{d}}$ ) when inheritances are held fixed, which is wellknown from Theorem 2(a), here with index $t+1$ instead of $t$. This effect is now augmented by the potential change of inheritances $e_{i t+1}$, as the parent generation $t$ adapts to the tax. Obviously, the condition that inheritances increase with abilities now implies a positive welfare effect only if it is not outweighed by the change of $\mathrm{e}_{\mathrm{it}+1}$. Note that $\partial \mathrm{e}_{\mathrm{it}+1} / \partial \tau_{\mathrm{et}+1}$ may have any sign, depending on the elasticity of net bequests $b_{i t}^{\text {net }}=b_{i t}\left(1-\tau_{\text {et+t }}\right)$. In case of an elasticity of 1 , as with Cobb-Douglas preferences over $c_{i t}$ and $b_{i t}^{\text {net }}$ (and separability with respect to labor time), gross bequests remain unchanged and $\partial \mathrm{e}_{\mathrm{it}+1} / \partial \tau_{\mathrm{et}+1}$ is zero. ${ }^{15}$ Finally, a change of inheritances $e_{i t+1}$ clearly affects resources of generation $t+1$. This effect (multiplier $\tilde{\lambda}_{t+1}^{\mathrm{d}}$ ) may have any sign, it is again zero for Cobh-Douglas preferences.

Altogether, we find that the welfare effect of an increase of the inheritance tax $\tau_{\mathrm{et}+1}$ is diminished, if this increase is anticipated by the previous generation $\mathrm{t}$ and individuals care for net instead of gross bequests. A direct negative effect on the parent generation occurs, as a consequence of the fact that bequests (and, hence, their reduction through the inheritance tax) appear twice in the social welfare function, while the repayment of the tax revenues (the reduction of the income tax) occurs only once.

Theorem 3(b) states that, as already discussed above, anticipation does in no way change the condition which is decisive for the desirability of the full expenditure tax $\tau_{t+1}$. Let us

14 For quasilinear preferences (introduced in Section 3) the sign is negative, because the marginal utility of net income is constant and net bequests are a normal good, i.e. $b_{\mathrm{Ht}}^{\text {net }}>\mathrm{b}_{\mathrm{Ht}}^{\text {net }}[\mathrm{L}]$.

15 Given that the rule guiding how gross bequests are allocated to generation $\mathrm{t}+1$ does not depend on $\tau_{\mathrm{et}+1}$. Then unchanged gross bequests $b_{\mathrm{Lt}}$ and $b_{\mathrm{Ht}}$ mean unchanged gross inheritances $\mathrm{e}_{\mathrm{Lt}+1}$ and $\mathrm{e}_{\mathrm{Ht}+1}$. 
also mention an obvious implication of the bequest-as-consumption motive: taxes introduced in some period never have repercussions on generations living more than one period earlier, even if individuals care for net bequests.

In a last step we note that there is an obvious similarity between the tax $\tau_{\mathrm{et}+1}$ levied on inheritances of generation $\mathrm{t}+1$ and a tax $\tau_{\mathrm{bt}}$ levied on bequests left by generation $\mathrm{t}$. In fact, both are equivalent, if the revenues of $\tau_{b t}$ run into the budget of generation $t+1$ (as it was assumed above for the revenues of $\left.\tau_{\mathrm{et}+1}\right)$, and Theorem $3 \mathrm{a}$ applies. However, the situation is different, if the revenues of the bequest tax $\tau_{\mathrm{bt}}$ are modeled to remain within generation $\mathrm{t}$ (that is, to reduce the income tax burden of the bequeathing generation). In this case we are basically back to the model underlying Theorem 2, the difference being that now we consider a specific tax on bequests, while in Theorem 2 we analyzed the consequences of an inheritance and an expenditure tax, resp., whose revenues are redistributed within the parent generation $\mathrm{t}$. To analyze the effect of a tax on bequests $\tau_{\mathrm{bt}}$, we replace $\tau_{\mathrm{t}}$ by $\tau_{\mathrm{bt}}$ in the indirect utility function and use

$$
v_{t}^{i}\left(x_{i t}, z_{i t}, e_{i t}, \tau_{\text {et }}, \tau_{b t}\right) \equiv \max \left\{u\left(c_{i t}, b_{i t}, z_{i t} / \omega_{i t}\right) \mid c_{i t}+b_{i t}\left(1+\tau_{b t}\right) \leq x_{i t}+\left(1-\tau_{\text {et }}\right) e_{i t}\right\}
$$

in the objective (6) and in the self-selection constraint (8). Modifying the government budget constraint (7) to include the tax revenues from $\tau_{\mathrm{bt}}$ instead of $\tau_{\mathrm{t}}$, maximization of (6) subject to the constraints leads us to (the index com denotes compensated demand)

Theorem 4: In a dynamic model, the welfare effect of a marginal increase of $\tau_{\mathrm{bt}}$ in some period t, reads:

$$
\begin{aligned}
\frac{\partial \mathrm{S}^{\mathrm{d}}}{\partial \tau_{\mathrm{bt}}}= & \mu^{\mathrm{d}} \frac{\partial \mathrm{v}_{\mathrm{t}}^{\mathrm{H}}[\mathrm{L}]}{\partial \mathrm{x}_{\mathrm{Lt}}}\left(\mathrm{b}_{\mathrm{Ht}}[\mathrm{L}]-\mathrm{b}_{\mathrm{Lt}}\right)+(1+\gamma)^{-1}\left(\frac{\partial \mathrm{W}}{\partial \mathrm{b}_{\mathrm{Lt}}} \frac{\partial \mathrm{b}_{\mathrm{Lt}}^{\mathrm{com}}}{\partial \tau_{\mathrm{bt}}}+\frac{\partial \mathrm{W}}{\partial \mathrm{b}_{\mathrm{Ht}}} \frac{\partial \mathrm{b}_{\mathrm{Ht}}^{\mathrm{com}}}{\partial \tau_{\mathrm{bt}}}\right) \\
& +\lambda^{\mathrm{d}} \tau_{\mathrm{bt}}\left(\frac{\partial \mathrm{b}_{\mathrm{Lt}}^{\mathrm{com}}}{\partial \tau_{\mathrm{bt}}}+\frac{\partial \mathrm{b}_{\mathrm{Ht}}^{\mathrm{com}}}{\partial \tau_{\mathrm{bt}}}\right) .
\end{aligned}
$$

Proof: see Appendix.

The first term occurring on the RHS represents a positive effect similar to that found in Theorem 2 for $\tau_{t}$ and $\tau_{\text {et }}$, resp.: Given that $\mathrm{e}_{\mathrm{Ht}}>\mathrm{e}_{\mathrm{Lt}}$ we will also have $\mathrm{b}_{\mathrm{Ht}}[\mathrm{L}]>\mathrm{b}_{\mathrm{Lt}}$ (if bequest are a normal good, larger inheritances received by the high-able individual of 
generation $t$ induce larger bequests, even if she chooses the same gross- and net-income bundle as the low-able individual). However, due to the distortion of the bequest decision, we now have a negative compensated effect ${ }^{16}$ on welfare of future generations as well as on the resource constraint (multiplier $\lambda^{\mathrm{d}}$ ). The latter represents a standard deadweight-loss effect, which is zero if $\tau_{\mathrm{bt}}=0$. As known from above, an inheritance tax $\tau_{\mathrm{et}}$ as well as an expenditure tax $\tau_{\mathrm{t}}$ can avoid this distortion and are, hence, preferable tax instruments.

\section{Taxation of inheritances in a stochastic framework}

As already mentioned, an objection against the models of Section 2 could be that with a fixed one-to-one relation between abilities and inherited wealth it is possible to identify individuals by their inherited wealth or by their expenditures (given these are observable) and to impose a first-best tax. In reality, no tax authority follows this strategy, because the relation between inherited wealth (or expenditures) and skills is not fixed, but stochastic. In order to capture this issue, we now assume that inherited wealth is random and prove a stochastic version of Theorem 2, where still a positive relation between inherited wealth and abilities is decisive.

In order to make the model tractable, we assume in this Section that the utility function (identical for all individuals) is quasilinear, i.e., $u(c, b, 1)=\varphi(c, b)+\psi(1)$, where $\varphi: \mathbb{R}^{2} \rightarrow \mathbb{R}$ is concave and linear-homogeneous with $\partial \varphi / \partial \mathrm{c}>0, \partial \varphi / \partial \mathrm{b}>0$, and $\psi: \mathbb{R} \rightarrow \mathbb{R}$ is strictly concave with $\psi^{\prime}<0$. One observes immediately that for quasilinear utility the following statements hold for indirect utility (5) and demand: ${ }^{17}$

(q1) $\partial \mathrm{v} / \partial \mathrm{x}=\rho /(1+\tau) . \quad \rho$ is a constant, independent of ability $\omega$ and $\mathrm{x}, \mathrm{z}$. $\partial \mathrm{v} / \partial \mathrm{e}=\rho\left(1-\tau_{\mathrm{e}}\right) /(1+\tau)$

(q2) $\partial \mathrm{b} / \partial \mathrm{z}=\partial \mathrm{c} / \partial \mathrm{z}=0$. For given net income, demand is independent of gross income (i. e., labor supply).

(q3) $\mathrm{c}=\alpha_{\mathrm{c}}\left(\mathrm{x}+\left(1-\tau_{\mathrm{e}}\right) \mathrm{e}\right) /(1+\tau) \quad$ and $\mathrm{b}=\alpha_{\mathrm{b}}\left(\mathrm{x}+\left(1-\tau_{\mathrm{e}}\right) \mathrm{e}\right) /(1+\tau) . \quad \alpha_{\mathrm{c}}, \alpha_{\mathrm{b}} \quad$ are the constant shares of consumption and bequests in the available budget, after correcting for $\tau$, with $\alpha_{c}+\alpha_{b}=1$.

\footnotetext{
16 As is well-known, own compensated price effects are negative.

17 For simplicity we drop the indices referring to the types and periods.
} 
The most important consequence of (q1) is that the self-selection constraint is independent of income effects, that is, of inheritances (see (11) later on).

We generalize the model by introducing $\mathrm{n}$ (not just two) different types of individuals, characterized by their earning abilities $\omega_{\text {it }}>0, i=1, \ldots, n$, with $\omega_{\text {it }}<\omega_{i+1 t}$ in period t.

Let some tax rates $\tau_{\mathrm{et}}, \tau_{\mathrm{t}}$ (possibly zero) be given in period $\mathrm{t}$. At the beginning of this period the planning tax authority determines the optimum tax on labor income (that is, the optimum bundles $x_{i t}, z_{i t}, i=1, \ldots, n$ ) and decides whether a change of the tax rates $\tau_{\text {et }}, \tau_{t}$ (or their introduction) is desirable.

When making the decision, the planner knows the ability levels $\omega_{1 t}, \ldots, \omega_{\mathrm{nt}}$ of the individuals of generation $\mathrm{t}$ period, but cannot identify individuals. Moreover, we assume that the planner knows the aggregate amount of bequests, $e_{t}^{a g}$, left to the generation $t$ in total (no uncertainty regarding aggregate resources in period t exists). There is, however, only a stochastic relation between the ability level and the amount of inheritance an individual receives. Thus, the planner cannot, even when the realization of inheritances is known, infer the ability type of the receiving individual. (Nor is identification possible from the expenditures of an individual.)

More formally, we assume that there exists a (finite) number $\mathrm{k}$ of ways of how the aggregate amount $e_{t}^{a g}$ may be distributed to the individuals of generation $t$, where each specific allocation $\mathrm{j}, \mathrm{j}=1, \ldots \mathrm{k}$, occurs with probability $\kappa_{\mathrm{jt}}\left(\right.$ with $\left.\kappa_{1 \mathrm{t}}+\ldots+\kappa_{\mathrm{kt}}=1\right)$ and transfers $e_{i t}^{j}$ to individual $i$, with $e_{1 t}^{j}+\ldots+e_{n t}^{j}=e_{t}^{a g}$. The possible realizations and their probabilities are known.

Facing uncertainty, the planner wants to maximize expected social welfare in period t. With $f_{1 t}>f_{2 t}>\ldots>f_{n t}>0$ being the weights of the different types in the social objective ${ }^{18}$, the problem to determine the optimum income tax (that is, the bundles $\mathrm{x}_{\mathrm{it}}, \mathrm{z}_{\mathrm{it}}$ ) reads, for given $\tau_{\text {et }}, \tau_{t}$ :

18 Note that with quasilinear preferences the marginal utility of income is identical for all individuals; therefore a utilitarian objective with equal weights would not imply downward redistribution of income. 


$$
\begin{aligned}
& \max _{\mathrm{x}_{\mathrm{it}}, \mathrm{z}_{\mathrm{it}}} \sum_{\mathrm{j}=1}^{\mathrm{k}}\left(\sum_{\mathrm{i}=1}^{\mathrm{n}} \mathrm{f}_{\mathrm{it}} \mathrm{v}_{\mathrm{t}}^{\mathrm{i}}\left(\mathrm{x}_{\mathrm{it}}, \mathrm{z}_{\mathrm{it}}, \mathrm{e}_{\mathrm{it}}^{\mathrm{j}}, \tau_{\mathrm{et}}, \tau_{\mathrm{t}}\right)\right) \kappa_{\mathrm{jt}}+(1+\gamma)^{-1} \sum_{\mathrm{j}=1}^{\mathrm{k}} \mathrm{W}\left(\mathrm{b}_{1 \mathrm{t}}^{\mathrm{j}}, \ldots, \mathrm{b}_{\mathrm{nt}}^{\mathrm{j}}\right) \kappa_{\mathrm{jt}}, \\
& \text { s.t. } \sum_{i=1}^{n} x_{i t} \leq \sum_{i=1}^{n} z_{i t}+\tau_{\text {et }} \sum_{j=1}^{k}\left(\sum_{i=1}^{n} e_{i t}^{j}\right) \kappa_{j t}+\tau_{t} \sum_{j=1}^{k}\left(\sum_{i=1}^{n}\left(c_{i t}^{j}+b_{i t}^{j}\right)\right) \kappa_{j t}-g_{t} \text {, } \\
& \frac{\rho}{1+\tau_{t}}\left(x_{i t}-x_{i-1 t}\right) \geq \psi\left(\frac{z_{i-1 t}}{\omega_{i}}\right)-\psi\left(\frac{z_{i t}}{\omega_{i}}\right), \quad i=2, \ldots, n .
\end{aligned}
$$

Here $c_{i t}^{j}, b_{i t}^{j}$ denote consumption of individual $i$ and bequests left by her, in case that allocation $\mathrm{j}$ of inheritances is realized. Moreover, similar to the formulation in Subsection 2.2, W describes how future social welfare is influenced by the bequests of generation $\mathrm{t}$. We have assumed that only the self-selection constraints (12) for the respective higher-able individuals are relevant in the optimum. ${ }^{19}$ This is justified, if the social objective implies downward redistribution, which follows from our assumption $f_{i t}>f_{i+1 t}$.

We have to check, whether this problem is well defined, that is, whether it can be solved by the planner without knowing the actual realization of the inheritances. For this, the constraints (10) and (11) must be independent of the realization. As the $e_{i t}^{j}$ do not appear in the self-selection constraints (11) (due to the consequence (q1) of quasilinear utility, as already mentioned), the required independence is clearly fulfilled for these constraints. Moreover, exchanging the order of summation in the resource constraint (10) and using the property (q3) of quasilinear utility, it can be written as

$$
\sum_{i=1}^{n} x_{i t} \leq \sum_{i=1}^{n} z_{i t}+\tau_{e t} e_{t}^{a g}+\frac{\tau_{t}}{1+\tau_{t}}\left[\sum_{i=1}^{n} x_{i t}+\left(1-\tau_{e t}\right) e_{t}^{a g}\right]-g_{t}
$$

Thus, the resource constraint is independent of the particular realization of the inheritances as well. Only the aggregate amount of inheritances matters, which we assume to be known. This proves

Lemma 2: The optimum bundles $\left(x_{i t}, z_{i t}\right), i=1, \ldots, n$ of problem $(10)-(12)$ can be determined independently of the particular realization of individual inheritances $e_{i t}^{j}$.

\footnotetext{
19 It is well-known that only the self-selection constraints of pairs of individuals with adjacent ability levels
} need to be considered. See, e. g. Brunner 1989. 
To derive the following theorem, we need the assumption that $\mathrm{W}$ has some "quasilinear property", namely that, given any $i$, the derivatives $\partial \mathrm{W} / \partial \mathrm{b}_{\mathrm{it}}^{\mathrm{j}}$ are independent of $\mathrm{j}$. In other words, the marginal welfare effect of an increase of an individual's bequests on the welfare of future generations is constant and is, in particular independent of the specific realization of inheritances received by generation $\mathrm{t}$. This is obviously fulfilled, if $\mathrm{W}$ is a discounted sum of future expected social welfare (see footnote 10), with quasilinear individual utility in each period.

Let now $S^{r}\left(\tau_{\text {et }}, \tau_{t}\right)$ be the optimum value of (10) subject to (11) and (12), for given $\tau_{\text {et }}$, $\tau_{t}$, and let $\bar{e}_{i t}$ denote the expected value of the inheritances $e_{i t}^{j}$ which individual $i$ of generation $t$ receives. As the criteria for a change (or the introduction) of taxes on inheritances and/or full expenditures we find

Theorem 5: With stochastic inheritances, the welfare effect of a marginal increase of $\tau_{\text {et }}$ and $\tau_{\mathrm{t}}$, resp., in some period $\mathrm{t}$, reads:
(a) $\frac{\partial \mathrm{S}^{\mathrm{r}}}{\partial \tau_{\mathrm{et}}}=\frac{\rho}{1+\tau_{\mathrm{t}}} \sum_{\mathrm{i}=2}^{\mathrm{n}} \mu_{\mathrm{i}}^{\mathrm{r}}\left(\overline{\mathrm{e}}_{\mathrm{it}}-\overline{\mathrm{e}}_{\mathrm{i}-1 \mathrm{t}}\right)$,
(b) $\frac{\partial S^{\mathrm{r}}}{\partial \tau_{\mathrm{t}}}=\frac{\left(1-\tau_{\mathrm{et}}\right) \rho}{\left(1+\tau_{\mathrm{t}}\right)^{2}} \sum_{\mathrm{i}=2}^{\mathrm{n}} \mu_{\mathrm{i}}^{\mathrm{r}}\left(\overline{\mathrm{e}}_{\mathrm{it}}-\overline{\mathrm{e}}_{\mathrm{i}-1 \mathrm{t}}\right)$.

Proof: see Appendix.

Thus, we arrive at a direct stochastic analogon of Theorem 2, referring to expected values instead of deterministic inheritances. A sufficient (but not necessary) condition for the desirability of a tax on inheritances (or on full expenditures) is that the order of expected inheritances is the same as the order of earning abilities, because then the right-hand sides of (a) and (b) are positive. ${ }^{20}$

20 One can show that a sufficient and necessary condition for the desirability of these taxes is that the social marginal valuation of individual i's income (including its value for all future generations via bequests), i.e., $\left.\left[f_{i t} \rho+(1+\gamma)^{-1} \alpha_{b} \partial W / \partial b_{i t}\right] /\left(1+\tau_{t}\right)\right)$, is negatively correlated with expected inheritance $\bar{e}_{i t}$. This result is obtained by solving (A25) - (A27) in the Appendix for $\mu_{i}^{r}$ and using this expression together with the definition of the covariance in the RHS's of (a) and (b). 


\section{Conclusion}

The essential argument advocated in this paper is that in order to understand the role of estate or inheritance taxation one has to start with a model where differences in initial wealth already exist, as a result of unequal estates left by previous generations. In contrast, most contributions to the literature on bequest taxation consider the standard optimumtaxation model, where individuals differ only in earning abilities, not in initial wealth. In such a framework the Atkinson-Stiglitz result applies, saying that there is no role for any indirect tax (given weak separability), hence also not for a bequest tax. We think that this model, even if it might be seen as being appropriate for some "first" generation, whose members did not inherit anything, does certainly not apply for the present discussion of the bequest or inheritance tax. We live in a world where difference in initial wealth exist, originated by bequests left by prior generations.

Drawing on this observation, which is central to the equality-of-opportunity argument, we have studied the role of inheritance taxation in an optimum-taxation framework with a bequest-as-consumption motive. In particular, we have worked out how different generations are affected by this tax. More generally, our results shed new light on the role of indirect taxes as well as of a tax on inherited wealth in combination with an optimum nonlinear income tax. The two main messages are the following:

First, in a static setting it is desirable, according to a utilitarian social objective, to shift some tax burden from labor income to initial wealth, if initial wealth increases with earning abilities. From a theoretical point of view, this result is a consequence of the information constraint which motivates income taxation in the Mirrlees-model: if the tax authority could observe individual earning abilities, it would impose the tax directly on these, as a (differentiated) first-best instrument. Given that this is impossible, it seems natural, then, that the authority can improve the tax system by use of information (i.e. imposing a tax) on inherited wealth (in addition to information on income), in case that it is observable and correlated with abilities. (In fact, if the correlation were negative, wealth should be subsidized.) Equivalently, a uniform tax on consumption plus bequests is also appropriate for this purpose. 
Secondly, this result remains unchanged in a dynamic model in which the social welfare function accounts for effects on future generations: these effects cancel out when the optimum labor income tax is adapted accordingly. This is the final result for the case that a uniform tax on consumption plus bequests is imposed, as a surrogate for a tax on inherited wealth. In case that inheritances are taxed directly, an additional effect hast to be observed: if the parent individuals care for net instead of gross bequests (and anticipate the tax falling on the recipients of the wealth transfer in the next generation), then the bequest decision of the previous generation is affected and a further welfare effect arises, which is negative, because of "double-counting" of bequests. The nature of this effect depends on whether the tax revenues run into the public budget of the parents or of the descendants.

Obviously, for the second message the assumption of the joy-of-giving motive for leaving bequests is important. With this motive, individuals care for the amount they leave to their descendants (and possibly for its reduction through an inheritance tax). However, they do not care for which purpose the descendants use their inheritance, nor, in particular, to which extent the descendants are subjected to a tax when they use the inherited amount for own consumption as well as for bequests in favor of a further generation. This is a reasonable standard assumption; it implies that a uniform tax on consumption and bequests produces no negative effects for the parent generation.

Finally, we have demonstrated that the results on the taxation of inheritances remain essentially valid, if there is a stochastic instead of a deterministic connection between abilities and inheritances: taxation is desirable, if expected inheritances of more able individuals are larger.

Throughout this paper we have assumed that earning abilities are exogenous. In reality, of course, they depend on human capital investments, which are financed out of the parents' budget, as are inheritances of non-human capital. Given that both increase with the budget, this provides an argument for the positive relation between abilities and inherited wealth within the generation of heirs. ${ }^{21}$

21 Brunner and Pech (2010b) have shown that indeed such a situation results as the outcome of a process with stochastic transition of abilities and wealth over generations, if all descendants are more probable to have their parent's ability rank than any other. 
When investigating the welfare consequences of inheritance taxation, we confined our analysis to a uniform tax on consumption plus bequests and to a proportional tax on inherited wealth, and proved that, in principle, they are equivalent. We did not consider the possibility that a differentiation of tax rates according to the type of expenditures might increase welfare further, as it does in the Atkinson-Stiglitz model. Moreover, also the welfare consequences of other tax schedules, for instance a linear (instead of a nonlinear) income tax or a nonlinear tax on inheritances, deserve further analysis. 


\section{Appendix}

\section{Proof of Theorem 1}

(a) The Lagrangian to the maximization problem (2) - (4) reads

$$
\begin{aligned}
\mathrm{L}= & \mathrm{f}_{\mathrm{L}} \mathrm{v}^{\mathrm{L}}\left(\mathrm{x}_{\mathrm{L}}, \mathrm{z}_{\mathrm{L}}, \mathrm{e}_{\mathrm{L}}, \tau_{\mathrm{e}}, \tau\right)+\mathrm{f}_{\mathrm{H}} \mathrm{v}^{\mathrm{H}}\left(\mathrm{x}_{\mathrm{H}}, \mathrm{z}_{\mathrm{H}}, \mathrm{e}_{\mathrm{H}}, \tau_{\mathrm{e}}, \tau\right)- \\
& -\lambda\left(\mathrm{x}_{\mathrm{L}}+\mathrm{x}_{\mathrm{H}}-\mathrm{z}_{\mathrm{L}}-\mathrm{z}_{\mathrm{H}}-\tau_{\mathrm{e}}\left(\mathrm{e}_{\mathrm{L}}+\mathrm{e}_{\mathrm{H}}\right)-\tau\left(\mathrm{c}_{\mathrm{L}}(\cdot)+\mathrm{b}_{\mathrm{L}}(\cdot)+\mathrm{c}_{\mathrm{H}}(\cdot)+\mathrm{b}_{\mathrm{H}}(\cdot)\right)+\mathrm{g}\right)+ \\
& +\mu\left(\mathrm{v}^{\mathrm{H}}\left(\mathrm{x}_{\mathrm{H}}, \mathrm{z}_{\mathrm{H}}, \mathrm{e}_{\mathrm{H}}, \tau_{\mathrm{e}}, \tau\right)-\mathrm{v}^{\mathrm{H}}\left(\mathrm{x}_{\mathrm{L}}, \mathrm{z}_{\mathrm{L}}, \mathrm{e}_{\mathrm{H}}, \tau_{\mathrm{e}}, \tau\right)\right)
\end{aligned}
$$

which gives us the first-order condition with respect to $\mathrm{x}_{\mathrm{L}}, \mathrm{x}_{\mathrm{H}}, \mathrm{i}=\mathrm{L}, \mathrm{H}$ (we use the abbreviation $\left.\mathrm{v}^{\mathrm{H}}[\mathrm{L}] \equiv \mathrm{v}^{\mathrm{H}}\left(\mathrm{x}_{\mathrm{L}}, \mathrm{z}_{\mathrm{L}}, \mathrm{e}_{\mathrm{H}}, \tau_{\mathrm{e}}, \tau\right)\right)$ :

$$
\begin{aligned}
& \mathrm{f}_{\mathrm{L}} \frac{\partial \mathrm{v}^{\mathrm{L}}}{\partial \mathrm{x}_{\mathrm{L}}}-\lambda+\lambda \tau\left(\frac{\partial \mathrm{c}_{\mathrm{L}}}{\partial \mathrm{x}_{\mathrm{L}}}+\frac{\partial \mathrm{b}_{\mathrm{L}}}{\partial \mathrm{x}_{\mathrm{L}}}\right)-\mu \frac{\partial \mathrm{v}^{\mathrm{H}}[\mathrm{L}]}{\partial \mathrm{x}_{\mathrm{L}}}=0, \\
& \mathrm{f}_{\mathrm{H}} \frac{\partial \mathrm{v}^{\mathrm{H}}}{\partial \mathrm{x}_{\mathrm{H}}}-\lambda+\lambda \tau\left(\frac{\partial \mathrm{c}_{\mathrm{H}}}{\partial \mathrm{x}_{\mathrm{H}}}+\frac{\partial \mathrm{b}_{\mathrm{H}}}{\partial \mathrm{x}_{\mathrm{H}}}\right)+\mu \frac{\partial \mathrm{v}^{\mathrm{H}}}{\partial \mathrm{x}_{\mathrm{H}}}=0 .
\end{aligned}
$$

Using the Envelope Theorem we get for the optimal value function $\mathrm{S}\left(\tau_{\mathrm{e}}, \tau\right)$

$$
\begin{aligned}
\frac{\partial \mathrm{S}}{\partial \tau_{\mathrm{e}}}= & \mathrm{f}_{\mathrm{L}} \frac{\partial \mathrm{v}^{\mathrm{L}}}{\partial \tau_{\mathrm{e}}}+\mathrm{f}_{\mathrm{H}} \frac{\partial \mathrm{v}^{\mathrm{H}}}{\partial \tau_{\mathrm{e}}}+\lambda\left(\mathrm{e}_{\mathrm{L}}+\mathrm{e}_{\mathrm{H}}\right)+\lambda \tau\left(\frac{\partial \mathrm{c}_{\mathrm{L}}}{\partial \tau_{\mathrm{e}}}+\frac{\partial \mathrm{b}_{\mathrm{L}}}{\partial \tau_{\mathrm{e}}}+\frac{\partial \mathrm{c}_{\mathrm{H}}}{\partial \tau_{\mathrm{e}}}+\frac{\partial \mathrm{b}_{\mathrm{H}}}{\partial \tau_{\mathrm{e}}}\right)+ \\
& +\mu\left(\frac{\partial \mathrm{v}^{\mathrm{H}}}{\partial \tau_{\mathrm{e}}}-\frac{\partial \mathrm{v}^{\mathrm{H}}[\mathrm{L}]}{\partial \tau_{\mathrm{e}}}\right) .
\end{aligned}
$$

We use $\partial \mathrm{v}^{\mathrm{i}} / \partial \tau_{\mathrm{e}}=-\mathrm{e}_{\mathrm{i}} \partial \mathrm{v}^{\mathrm{i}} / \partial \mathrm{x}_{\mathrm{i}}, \partial \mathrm{v}^{\mathrm{H}}[\mathrm{L}] / \partial \tau_{\mathrm{e}}=-\mathrm{e}_{\mathrm{H}} \partial \mathrm{v}^{\mathrm{H}}[\mathrm{L}] / \partial \mathrm{x}_{\mathrm{L}}, \partial \mathrm{c}_{\mathrm{i}} / \partial \tau_{\mathrm{e}}=-\mathrm{e}_{\mathrm{i}} \partial \mathrm{c}_{\mathrm{i}} / \partial \mathrm{x}_{\mathrm{i}}$, $\partial \mathrm{b}_{\mathrm{i}} / \partial \tau_{\mathrm{e}}=-\mathrm{e}_{\mathrm{i}} \partial \mathrm{b}_{\mathrm{i}} / \partial \mathrm{x}_{\mathrm{i}}$, compute $\mathrm{f}_{\mathrm{i}} \partial \mathrm{v}^{\mathrm{i}} / \partial \mathrm{x}_{\mathrm{i}}, \mathrm{i}=\mathrm{L}, \mathrm{H}$, from (A1) and (A2) and transform, thus, (A3) to

$$
\frac{\partial \mathrm{S}}{\partial \tau_{\mathrm{e}}}=\mu \frac{\partial \mathrm{v}^{\mathrm{H}}[\mathrm{L}]}{\partial \mathrm{x}_{\mathrm{L}}}\left(\mathrm{e}_{\mathrm{H}}-\mathrm{e}_{\mathrm{L}}\right) .
$$

(b) We determine

$$
\begin{aligned}
\frac{\partial \mathrm{S}}{\partial \tau}= & \mathrm{f}_{\mathrm{L}} \frac{\partial \mathrm{v}^{\mathrm{L}}}{\partial \tau}+\mathrm{f}_{\mathrm{H}} \frac{\partial \mathrm{v}^{\mathrm{H}}}{\partial \tau}+\lambda\left(\mathrm{c}_{\mathrm{L}}+\mathrm{b}_{\mathrm{L}}+\mathrm{c}_{\mathrm{H}}+\mathrm{b}_{\mathrm{H}}\right)+ \\
& +\lambda \tau\left(\frac{\partial \mathrm{c}_{\mathrm{L}}}{\partial \tau}+\frac{\partial \mathrm{b}_{\mathrm{L}}}{\partial \tau}+\frac{\partial \mathrm{c}_{\mathrm{H}}}{\partial \tau}+\frac{\partial \mathrm{b}_{\mathrm{H}}}{\partial \tau}\right)+\mu \frac{\partial \mathrm{v}^{\mathrm{H}}}{\partial \tau}-\mu \frac{\partial \mathrm{v}^{\mathrm{H}}[\mathrm{L}]}{\partial \tau} .
\end{aligned}
$$


The individual i's budget equation can be written as $c_{i}+b_{i}=B_{i}$, where $\mathrm{B}_{\mathrm{i}} \equiv\left(\mathrm{x}_{\mathrm{i}}+\left(1-\tau_{\mathrm{e}}\right) \mathrm{e}_{\mathrm{i}}\right) /(1+\tau)$. Thus, $\partial \mathrm{c}_{\mathrm{i}} / \partial \tau=\left(\partial \mathrm{c}_{\mathrm{i}} / \partial \mathrm{B}_{\mathrm{i}}\right)\left(\partial \mathrm{B}_{\mathrm{i}} / \partial \tau\right)=-\left(\mathrm{c}_{\mathrm{i}}+\mathrm{b}_{\mathrm{i}}\right) \partial \mathrm{c}_{\mathrm{i}} / \partial \mathrm{x}_{\mathrm{i}}$ (use $\left.\partial \mathrm{B}_{\mathrm{i}} / \partial \tau=-\left(\mathrm{x}_{\mathrm{i}}+\left(1-\tau_{\mathrm{e}}\right) \mathrm{e}_{\mathrm{i}}\right) /(1+\tau)^{2}=-\left(\mathrm{c}_{\mathrm{i}}+\mathrm{b}_{\mathrm{i}}\right) /(1+\tau)\right)$ and $\left.\partial \mathrm{c}_{\mathrm{i}} / \partial \mathrm{x}_{\mathrm{i}}=\partial \mathrm{c}_{\mathrm{i}} / \partial \mathrm{B}_{\mathrm{i}} /(1+\tau)\right)$; equivalently $\partial \mathrm{b}_{\mathrm{i}} / \partial \tau=-\left(\mathrm{c}_{\mathrm{i}}+\mathrm{b}_{\mathrm{i}}\right) \partial \mathrm{b}_{\mathrm{i}} / \partial \mathrm{x}_{\mathrm{i}}$. Substituting these terms, together with $\partial \mathrm{v}^{\mathrm{i}} / \partial \tau=-\left(\mathrm{c}_{\mathrm{i}}+\mathrm{b}_{\mathrm{i}}\right) \partial \mathrm{v}^{\mathrm{i}} / \partial \mathrm{x}_{\mathrm{i}}, \quad \partial \mathrm{v}^{\mathrm{H}}[\mathrm{L}] / \partial \tau=-\left(\mathrm{c}_{\mathrm{H}}[\mathrm{L}]+\mathrm{b}_{\mathrm{H}}[\mathrm{L}]\right) \partial \mathrm{v}^{\mathrm{H}}[\mathrm{L}] / \partial \mathrm{x}_{\mathrm{L}}$ (where $\mathrm{c}_{\mathrm{H}}[\mathrm{L}]$, $b_{H}[L]$, resp., denotes consumption and bequests of individual $H$, having L's gross and net income), and with (A1),(A2) into (A4) yields

$$
\frac{\partial \mathrm{S}}{\partial \tau}=\mu \frac{\partial \mathrm{v}^{\mathrm{H}}[\mathrm{L}]}{\partial \mathrm{x}_{\mathrm{L}}}\left(\left(\mathrm{c}_{\mathrm{H}}[\mathrm{L}]+\mathrm{b}_{\mathrm{H}}[\mathrm{L}]\right)-\left(\mathrm{c}_{\mathrm{L}}+\mathrm{b}_{\mathrm{L}}\right)\right)
$$

Inserting the (transformed) budget equations of individual $\mathrm{H}$ when mimicking and of individual $\mathrm{L}$, i.e., $\quad \mathrm{c}_{\mathrm{H}}[\mathrm{L}]+\mathrm{b}_{\mathrm{H}}[\mathrm{L}]=\left(\mathrm{x}_{\mathrm{L}}+\left(1-\tau_{\mathrm{e}}\right) \mathrm{e}_{\mathrm{H}}\right) /(1+\tau) \quad$ and $\quad \mathrm{c}_{\mathrm{L}}+\mathrm{b}_{\mathrm{L}}=$ $=\left(x_{L}+\left(1-\tau_{e}\right) e_{L}\right) /(1+\tau)$ into (A5), we obtain the formula of Theorem 1(b). QED

\section{Proof of Theorem 2}

(a) From the Lagrangian to the optimization problem (5) - (7) we derive the first-order conditions with respect to $\mathrm{x}_{\mathrm{Lt}}, \mathrm{x}_{\mathrm{Ht}}$, where $\lambda^{\mathrm{d}}, \mu^{\mathrm{d}}$ are the multipliers corresponding to the resource constraint and to the self-selection constraint, resp.:

$$
\begin{aligned}
& \mathrm{f}_{\mathrm{Lt}} \frac{\partial \mathrm{v}_{\mathrm{t}}^{\mathrm{L}}}{\partial \mathrm{x}_{\mathrm{Lt}}}+(1+\gamma)^{-1} \frac{\partial \mathrm{W}}{\partial \mathrm{b}_{\mathrm{Lt}}} \frac{\partial \mathrm{b}_{\mathrm{Lt}}}{\partial \mathrm{x}_{\mathrm{Lt}}}-\lambda^{\mathrm{d}}+\lambda^{\mathrm{d}} \tau_{\mathrm{t}}\left(\frac{\partial \mathrm{c}_{\mathrm{Lt}}}{\partial \mathrm{x}_{\mathrm{Lt}}}+\frac{\partial \mathrm{b}_{\mathrm{Lt}}}{\partial \mathrm{x}_{\mathrm{Lt}}}\right)-\mu^{\mathrm{d}} \frac{\partial \mathrm{v}_{\mathrm{t}}^{\mathrm{H}}[\mathrm{L}]}{\partial \mathrm{x}_{\mathrm{Lt}}}=0 \\
& \mathrm{f}_{\mathrm{Ht}} \frac{\partial \mathrm{v}_{\mathrm{t}}^{\mathrm{H}}}{\partial \mathrm{x}_{\mathrm{Ht}}}+(1+\gamma)^{-1} \frac{\partial \mathrm{W}}{\partial \mathrm{b}_{\mathrm{Ht}}} \frac{\partial \mathrm{b}_{\mathrm{Ht}}}{\partial \mathrm{x}_{\mathrm{Ht}}}-\lambda^{\mathrm{d}}+\lambda^{\mathrm{d}} \tau_{\mathrm{t}}\left(\frac{\partial \mathrm{c}_{\mathrm{Ht}}}{\partial \mathrm{x}_{\mathrm{Ht}}}+\frac{\partial \mathrm{b}_{\mathrm{Ht}}}{\partial \mathrm{x}_{\mathrm{Ht}}}\right)+\mu^{\mathrm{d}} \frac{\partial \mathrm{v}_{\mathrm{t}}^{\mathrm{H}}}{\partial \mathrm{x}_{\mathrm{Ht}}}=0
\end{aligned}
$$

The derivative of the optimum-value function $S^{d}$ with respect $\tau_{\text {et }}$ is found by differentiating the Lagrangian:

$$
\begin{aligned}
\frac{\partial \mathrm{S}^{\mathrm{d}}}{\partial \tau_{\mathrm{et}}}= & \mathrm{f}_{\mathrm{Lt}} \frac{\partial \mathrm{v}_{\mathrm{t}}^{\mathrm{L}}}{\partial \tau_{\mathrm{et}}}+\mathrm{f}_{\mathrm{Ht}} \frac{\partial \mathrm{v}_{\mathrm{t}}^{\mathrm{H}}}{\partial \tau_{\mathrm{et}}}+(1+\gamma)^{-1}\left(\frac{\partial \mathrm{W}}{\partial \mathrm{b}_{\mathrm{Lt}}} \frac{\partial \mathrm{b}_{\mathrm{Lt}}}{\partial \tau_{\mathrm{et}}}+\frac{\partial \mathrm{W}}{\partial \mathrm{b}_{\mathrm{Ht}}} \frac{\partial \mathrm{b}_{\mathrm{Ht}}}{\partial \tau_{\mathrm{et}}}\right)+\lambda^{\mathrm{d}}\left(\mathrm{e}_{\mathrm{Lt}}+\mathrm{e}_{\mathrm{Ht}}\right)+ \\
& +\lambda^{\mathrm{d}} \tau_{\mathrm{t}}\left(\frac{\partial \mathrm{c}_{\mathrm{Lt}}}{\partial \tau_{\text {et }}}+\frac{\partial \mathrm{b}_{\mathrm{Lt}}}{\partial \tau_{\mathrm{et}}}+\frac{\partial \mathrm{c}_{\mathrm{Ht}}}{\partial \tau_{\mathrm{et}}}+\frac{\partial \mathrm{b}_{\mathrm{Ht}}}{\partial \tau_{\text {et }}}\right)+\mu^{\mathrm{d}}\left(\frac{\partial \mathrm{v}_{\mathrm{t}}^{\mathrm{H}}}{\partial \tau_{\text {et }}}-\frac{\partial \mathrm{v}_{\mathrm{t}}^{\mathrm{H}}[\mathrm{L}]}{\partial \tau_{\mathrm{et}}}\right) .
\end{aligned}
$$

By use of the formulas below (A3), (A8) can be transformed to 


$$
\begin{aligned}
\frac{\partial S^{\mathrm{d}}}{\partial \tau_{\mathrm{et}}}= & -\mathrm{f}_{\mathrm{Lt}} \mathrm{e}_{\mathrm{Lt}} \frac{\partial \mathrm{v}_{\mathrm{t}}^{\mathrm{L}}}{\partial \mathrm{x}_{\mathrm{Lt}}}-\mathrm{f}_{\mathrm{Ht}} \mathrm{e}_{\mathrm{Ht}} \frac{\partial \mathrm{v}_{\mathrm{t}}^{\mathrm{H}}}{\partial \mathrm{x}_{\mathrm{Ht}}}+(1+\gamma)^{-1}\left(-\mathrm{e}_{\mathrm{Lt}} \frac{\partial \mathrm{W}}{\partial \mathrm{b}_{\mathrm{Lt}}} \frac{\partial \mathrm{b}_{\mathrm{Lt}}}{\partial \mathrm{x}_{\mathrm{Lt}}}-\mathrm{e}_{\mathrm{Ht}} \frac{\partial \mathrm{W}}{\partial \mathrm{b}_{\mathrm{Ht}}} \frac{\partial \mathrm{b}_{\mathrm{Ht}}}{\partial \mathrm{x}_{\mathrm{Ht}}}\right)+ \\
& +\lambda^{\mathrm{d}}\left(\mathrm{e}_{\mathrm{Lt}}+\mathrm{e}_{\mathrm{Ht}}\right)+\lambda^{\mathrm{d}} \tau_{\mathrm{t}}\left[-\mathrm{e}_{\mathrm{Lt}}\left(\frac{\partial \mathrm{c}_{\mathrm{Lt}}}{\partial \mathrm{x}_{\mathrm{Lt}}}+\frac{\partial \mathrm{b}_{\mathrm{Lt}}}{\partial \mathrm{x}_{\mathrm{Lt}}}\right)-\mathrm{e}_{\mathrm{Ht}}\left(\frac{\partial \mathrm{c}_{\mathrm{Ht}}}{\partial \mathrm{x}_{\mathrm{Ht}}}+\frac{\partial \mathrm{b}_{\mathrm{Ht}}}{\partial \mathrm{x}_{\mathrm{Ht}}}\right)\right]- \\
& -\mu^{\mathrm{d}} \mathrm{e}_{\mathrm{Ht}}\left(\frac{\partial \mathrm{v}_{\mathrm{t}}^{\mathrm{H}}}{\partial \mathrm{x}_{\mathrm{Ht}}}-\frac{\partial \mathrm{v}_{\mathrm{t}}^{\mathrm{H}}[\mathrm{L}]}{\partial \mathrm{x}_{\mathrm{Lt}}}\right)
\end{aligned}
$$

Multiplying (A6), (A7) by $\mathrm{e}_{\mathrm{Lt}}, \mathrm{e}_{\mathrm{Ht}}$, resp., and substituting into (A9) gives us the formula of Theorem 2(a).

(b) Differentiating the Lagrangian of problem (5) - (7) with respect to $\tau_{t}$ gives:

$$
\begin{aligned}
\frac{\partial \mathrm{S}^{\mathrm{d}}}{\partial \tau_{\mathrm{t}}}= & \mathrm{f}_{\mathrm{Lt}} \frac{\partial \mathrm{v}_{\mathrm{t}}^{\mathrm{L}}}{\partial \tau_{\mathrm{t}}}+\mathrm{f}_{\mathrm{Ht}} \frac{\partial \mathrm{v}_{\mathrm{t}}^{\mathrm{H}}}{\partial \tau_{\mathrm{t}}}+(1+\gamma)^{-1}\left(\frac{\partial \mathrm{W}}{\partial \mathrm{b}_{\mathrm{Lt}}} \frac{\partial \mathrm{b}_{\mathrm{Lt}}}{\partial \tau_{\mathrm{t}}}+\frac{\partial \mathrm{W}}{\partial \mathrm{b}_{\mathrm{Ht}}} \frac{\partial \mathrm{b}_{\mathrm{Ht}}}{\partial \tau_{\mathrm{t}}}\right)+ \\
& +\lambda^{\mathrm{d}}\left[\mathrm{c}_{\mathrm{Lt}}+\mathrm{b}_{\mathrm{Lt}}+\mathrm{c}_{\mathrm{Ht}}+\mathrm{b}_{\mathrm{Ht}}+\tau_{\mathrm{t}}\left(\frac{\partial \mathrm{c}_{\mathrm{Lt}}}{\partial \tau_{\mathrm{t}}}+\frac{\partial \mathrm{b}_{\mathrm{Lt}}}{\partial \tau_{\mathrm{t}}}+\frac{\partial \mathrm{c}_{\mathrm{Ht}}}{\partial \tau_{\mathrm{t}}}+\frac{\partial \mathrm{b}_{\mathrm{Ht}}}{\partial \tau_{\mathrm{t}}}\right)\right]+ \\
& +\mu^{\mathrm{d}}\left(\frac{\partial \mathrm{v}_{\mathrm{t}}^{\mathrm{H}}}{\partial \tau_{\mathrm{t}}}-\frac{\partial \mathrm{v}_{\mathrm{t}}^{\mathrm{H}}[\mathrm{L}]}{\partial \tau_{\mathrm{t}}}\right) .
\end{aligned}
$$

By use of the formulas below (A4), (A10) can be transformed to

$$
\begin{aligned}
\frac{\partial \mathrm{S}^{\mathrm{d}}}{\partial \tau_{\mathrm{t}}}= & \sum_{\mathrm{i}=\mathrm{L}, \mathrm{H}}\left\{-\mathrm{f}_{\mathrm{it}}\left(\mathrm{c}_{\mathrm{it}}+\mathrm{b}_{\mathrm{it}}\right) \frac{\partial \mathrm{v}_{\mathrm{t}}^{\mathrm{i}}}{\partial \mathrm{x}_{\mathrm{it}}}-(1+\gamma)^{-1}\left(\left(\mathrm{c}_{\mathrm{it}}+\mathrm{b}_{\mathrm{it}}\right) \frac{\partial \mathrm{W}}{\partial \mathrm{b}_{\mathrm{it}}} \frac{\partial \mathrm{b}_{\mathrm{it}}}{\partial \mathrm{x}_{\mathrm{it}}}+\right.\right. \\
& +\lambda^{\mathrm{d}}\left[\mathrm{c}_{\mathrm{it}}+\mathrm{b}_{\mathrm{it}}-\tau_{\mathrm{t}}\left(\mathrm{c}_{\mathrm{it}}+\mathrm{b}_{\mathrm{it}}\right)\left(\frac{\partial \mathrm{c}_{\mathrm{it}}}{\partial \mathrm{x}_{\mathrm{it}}}+\frac{\partial \mathrm{b}_{\mathrm{it}}}{\partial \mathrm{x}_{\mathrm{it}}}\right]\right\}- \\
& \left.-\mu^{\mathrm{d}}\left(\mathrm{c}_{\mathrm{Ht}}+\mathrm{b}_{\mathrm{Ht}}\right) \frac{\partial \mathrm{v}_{\mathrm{t}}^{\mathrm{H}}}{\partial \mathrm{x}_{\mathrm{Ht}}}+\mu^{\mathrm{d}}\left(\mathrm{c}_{\mathrm{Ht}}[\mathrm{L}]+\mathrm{b}_{\mathrm{Ht}}[\mathrm{L}]\right) \frac{\partial \mathrm{v}_{\mathrm{t}}^{\mathrm{H}}[\mathrm{L}]}{\partial \mathrm{x}_{\mathrm{Lt}}}\right)
\end{aligned}
$$

Multiplying (A6), (A7) by $\left(\mathrm{c}_{\mathrm{Lt}}+\mathrm{b}_{\mathrm{Lt}}\right),\left(\mathrm{c}_{\mathrm{Ht}}+\mathrm{b}_{\mathrm{Ht}}\right)$, resp., and substituting into (A11) gives us

$$
\frac{\partial S^{d}}{\partial \tau_{t}}=\mu^{d} \frac{\partial v_{t}^{H}[L]}{\partial x_{L t}}\left(c_{H t}[L]+b_{H t}[L]-c_{L t}-b_{L t}\right),
$$

or, as shown in the proof of Theorem 1(b), the formula of Theorem 2(b).

QED 


\section{Proof of Theorem 3}

(a) If individuals care for net bequests, indirect utility of an individual i of generation $\mathrm{t}$ depends also on $\tau_{\text {et }+1}$ :

$$
\begin{aligned}
& v_{t}^{\mathrm{i}}\left(\mathrm{x}_{\mathrm{it}}, \mathrm{z}_{\mathrm{it}}, \mathrm{e}_{\mathrm{it}}, \tau_{\text {et }}, \tau_{\mathrm{t}}, \tau_{\text {et }+1}\right) \equiv \\
& \quad \max \left\{\mathrm{u}\left(\mathrm{c}_{\mathrm{it}}, \mathrm{b}_{\mathrm{it}}^{\text {net }}, \mathrm{z}_{\mathrm{it}} / \omega_{\mathrm{it}}\right) \mid\left(1+\tau_{\mathrm{t}}\right)\left(\mathrm{c}_{\mathrm{it}}+\mathrm{b}_{\mathrm{it}}^{\text {net }} /\left(1-\tau_{\mathrm{et}+1}\right)\right) \leq \mathrm{x}_{\mathrm{it}}+\left(1-\tau_{\mathrm{et}}\right) \mathrm{e}_{\mathrm{it}}\right\}
\end{aligned}
$$

Obviously, consumption $\mathrm{c}_{\mathrm{it}}(\cdot)$, net bequests $\mathrm{b}_{\mathrm{it}}^{\text {net }}(\cdot)$ and gross bequests $b_{i t}(\cdot)=b_{i t}^{\text {net }}(\cdot) /\left(1-\tau_{\text {et }+1}\right)$ depend on the same arguments as $v_{t}^{i}(\cdot)$. Moreover, gross inheritances $\mathrm{e}_{\mathrm{it}+1}(\cdot)$ are endogenous, they result from bequests of generation $\mathrm{t}$ via some (unspecified) rule and depend on the same arguments as $b_{\mathrm{Lt}}(\cdot)$ and $b_{\mathrm{Ht}}(\cdot)$.

When determining taxes for the periods $t$ and $t+1$, the tax authority has to observe the resource and the self-selection constraints for these periods:

$$
\begin{aligned}
& \sum_{i=L, H} x_{i t} \leq \sum_{i=L, H}\left[z_{i t}+\tau_{e t} e_{i t}+\tau_{t}\left(c_{i t}(\cdot)+b_{i t}^{\text {net }}(\cdot) /\left(1-\tau_{e t+1}\right)\right)\right]-g_{t}, \\
& \sum_{i=L, H} x_{i t+1} \leq \sum_{i=L, H}\left[z_{i t+1}+\tau_{e t+1} e_{i t+1}(\cdot)+\tau_{t+1}\left(c_{i t+1}(\cdot)+b_{i t+1}^{n e t}(\cdot) /\left(1-\tau_{e t+2}\right)\right)\right]-g_{t+1}, \\
& v_{t}^{H}\left(x_{H t}, z_{H t}, e_{H t}, \tau_{e t}, \tau_{t}, \tau_{e t+1}\right) \geq v_{t}^{H}\left(x_{L t}, z_{L t}, e_{H t}, \tau_{e t}, \tau_{t}, \tau_{e t+1}\right), \\
& v_{t+1}^{H}\left(x_{H t+1}, z_{H t+1}, e_{H t+1}(\cdot), \tau_{e t+1}, \tau_{t+1}, \tau_{e t+2}\right) \geq \\
& \quad v_{t+1}^{H}\left(x_{L t+1}, z_{L t+1}, e_{H t+1}(\cdot), \tau_{e t+1}, \tau_{t+1}, \tau_{e t+2}\right) .
\end{aligned}
$$

Using the Envelope Theorem we get for the optimum value function $\tilde{S}^{\mathrm{d}}\left(\tau_{\mathrm{et}}, \tau_{\mathrm{t}}, \tau_{\mathrm{et+1}}, \tau_{\mathrm{t}+1}\right)$ of the maximization problem (8), (A13) - (A16) $\left(\tilde{\lambda}_{\mathrm{t}}^{\mathrm{d}}, \tilde{\lambda}_{\mathrm{t}+1}^{\mathrm{d}}, \tilde{\mu}_{\mathrm{t}}^{\mathrm{d}}\right.$, $\tilde{\mu}_{t+1}^{\mathrm{d}}$ are the Lagrange multipliers corresponding to (A13) - (A16)):

$$
\begin{aligned}
\frac{\partial \tilde{S}^{\mathrm{d}}}{\partial \tau_{\mathrm{et}+1}}= & \sum_{\mathrm{i}=\mathrm{L}, \mathrm{H}} \mathrm{f}_{\mathrm{it}} \frac{\partial \mathrm{v}_{\mathrm{t}}^{\mathrm{i}}}{\partial \tau_{\mathrm{et}+1}}+(1+\gamma)^{-1} \sum_{\mathrm{i}} \mathrm{f}_{\mathrm{it}+1} \frac{\partial \mathrm{v}_{\mathrm{t}+1}^{\mathrm{i}}}{\partial \tau_{\mathrm{et}+1}}+(1+\gamma)^{-2}\left(\sum_{\mathrm{i}} \frac{\partial \mathrm{W}}{\partial \mathrm{b}_{\mathrm{it}+1}} \frac{\partial \mathrm{b}_{\mathrm{it}+1}}{\partial \tau_{\mathrm{et}+1}}\right)+ \\
& +\tilde{\lambda}_{\mathrm{t}}^{\mathrm{d}} \tau_{\mathrm{t}} \sum_{\mathrm{i}}\left(\frac{\partial \mathrm{c}_{\mathrm{it}}}{\partial \tau_{\mathrm{et}+1}}+\frac{\mathrm{b}_{\mathrm{it}}^{\mathrm{net}}}{\left(1-\tau_{\mathrm{et}+1}\right)^{2}}+\frac{1}{\left(1-\tau_{\mathrm{et}+1}\right)} \frac{\partial \mathrm{b}_{\mathrm{it}}^{\mathrm{net}}}{\partial \tau_{\mathrm{et}+1}}\right)+ \\
& +\tilde{\lambda}_{\mathrm{t}+1}^{\mathrm{d}} \sum_{\mathrm{i}}\left(\mathrm{e}_{\mathrm{it}+1}+\tau_{\mathrm{et}+1} \frac{\partial \mathrm{e}_{\mathrm{it}+1}}{\partial \tau_{\mathrm{et}+1}}\right)+\tilde{\lambda}_{\mathrm{t}+1}^{\mathrm{d}} \tau_{\mathrm{t}+1} \sum_{\mathrm{i}}\left(\frac{\partial \mathrm{c}_{\mathrm{it}+1}}{\partial \tau_{\mathrm{et}+1}}+\frac{1}{\left(1-\tau_{\mathrm{et}+2}\right)} \frac{\partial \mathrm{b}_{\mathrm{it}+1}^{\mathrm{net}}}{\partial \tau_{\mathrm{et}+1}}\right)+ \\
& +\tilde{\mu}_{\mathrm{t}}^{\mathrm{d}}\left(\frac{\partial \mathrm{v}_{\mathrm{t}}^{\mathrm{H}}}{\partial \tau_{\mathrm{et}+1}}-\frac{\partial \mathrm{v}_{\mathrm{t}}^{\mathrm{H}}[\mathrm{L}]}{\partial \tau_{\mathrm{et}+1}}\right)+\tilde{\mu}_{\mathrm{t}+1}^{\mathrm{d}}\left(\frac{\partial \mathrm{v}_{\mathrm{t}+1}^{\mathrm{H}}}{\partial \tau_{\mathrm{et}+1}}-\frac{\partial \mathrm{v}_{\mathrm{t}+1}^{\mathrm{H}}[\mathrm{L}]}{\partial \tau_{\mathrm{et}+1}}\right) .
\end{aligned}
$$


Differentiating the individual budget constraint of an individual $i$ with respect to $\tau_{\text {et+1 }}$ we obtain

$$
\frac{\partial \mathrm{c}_{\mathrm{it}}}{\partial \tau_{\mathrm{et}+1}}+\frac{\mathrm{b}_{\mathrm{it}}^{\mathrm{net}}}{\left(1-\tau_{\mathrm{et}+1}\right)^{2}}+\frac{1}{\left(1-\tau_{\mathrm{et}+1}\right)} \frac{\partial \mathrm{b}_{\mathrm{it}}^{\mathrm{net}}}{\partial \tau_{\mathrm{et}+1}}=0 .
$$

For shorter notation we introduce net inheritances $\mathrm{e}_{\mathrm{it}+1}^{\text {net }}(\cdot) \equiv \mathrm{e}_{\mathrm{it}+1}(\cdot)\left(1-\tau_{\mathrm{et}+1}\right)$, with $\partial \mathrm{e}_{\mathrm{it}+1}^{\mathrm{net}} / \partial \tau_{\mathrm{et}+1}=-\mathrm{e}_{\mathrm{it}+1}+\left(1-\tau_{\mathrm{et}+1}\right) \partial \mathrm{e}_{\mathrm{it}+1} / \partial \tau_{\mathrm{et}+1}$, thus $\partial \mathrm{e}_{\mathrm{it}+1} / \partial \tau_{\mathrm{et}+1}-\partial \mathrm{e}_{\mathrm{it}+1}^{\mathrm{net}} / \partial \tau_{\mathrm{et}+1}=\mathrm{e}_{\mathrm{it}+1}+$ $+\tau_{\mathrm{et}+1} \partial \mathrm{e}_{\mathrm{it}+1} / \partial \tau_{\mathrm{et}+1}$. Further, we have:

$\partial v_{t}^{\mathrm{i}} / \partial \tau_{\mathrm{et}+1}=-\left(\left(1+\tau_{\mathrm{t}}\right) \mathrm{b}_{\mathrm{it}}^{\text {net }} /\left(1-\tau_{\mathrm{et}+1}\right)^{2}\right) \partial \mathrm{v}_{\mathrm{t}}^{\mathrm{i}} / \partial \mathrm{x}_{\mathrm{it}}$ (use Roy's Lemma),

$\partial \mathrm{v}_{\mathrm{t}+1}^{\mathrm{i}} / \partial \tau_{\mathrm{et}+1}=\left(\partial \mathrm{e}_{\mathrm{it}+1}^{\mathrm{net}} / \partial \tau_{\mathrm{et}+1}\right)\left(\partial \mathrm{v}_{\mathrm{t}+1}^{\mathrm{i}} / \partial \mathrm{x}_{\mathrm{it}+1}\right), \partial \mathrm{c}_{\mathrm{it}+1} / \partial \tau_{\mathrm{et}+1}=\left(\partial \mathrm{e}_{\mathrm{it}+1}^{\mathrm{net}} / \partial \tau_{\mathrm{et}+1}\right)\left(\partial \mathrm{c}_{\mathrm{it}+1} / \partial \mathrm{x}_{\mathrm{it}+1}\right)$,

$\partial \mathrm{b}_{\mathrm{it}+1}^{\mathrm{net}} / \partial \tau_{\mathrm{et}+1}=\left(\partial \mathrm{e}_{\mathrm{it}+1}^{\mathrm{net}} / \partial \tau_{\mathrm{et}+1}\right)\left(\partial \mathrm{b}_{\mathrm{it}+1}^{\text {net }} / \partial \mathrm{x}_{\mathrm{it}+1}\right), \partial \mathrm{b}_{\mathrm{it}+1} / \partial \mathrm{x}_{\mathrm{it}+1}=\left(\partial \mathrm{b}_{\mathrm{it}+1}^{\mathrm{net}} / \partial \mathrm{x}_{\mathrm{it}+1}\right) /\left(1-\tau_{\mathrm{et}+2}\right)$.

By use of these formulas and of (A18), (A17) can be transformed to

$$
\begin{aligned}
\frac{\partial \tilde{S}^{\mathrm{d}}}{\partial \tau_{\mathrm{et}+1}}= & \frac{1+\tau_{\mathrm{t}}}{\left(1-\tau_{\mathrm{et}+1}\right)^{2}} \sum_{\mathrm{i}=\mathrm{L}, \mathrm{H}}-\mathrm{f}_{\mathrm{it}} \mathrm{b}_{\mathrm{it}}^{\mathrm{net}} \frac{\partial \mathrm{v}_{\mathrm{t}}^{\mathrm{i}}}{\partial \mathrm{x}_{\mathrm{it}}}+(1+\gamma)^{-1} \sum_{\mathrm{i}} \mathrm{f}_{\mathrm{it}+1} \frac{\partial \mathrm{v}_{\mathrm{t}+1}^{\mathrm{i}}}{\partial \mathrm{x}_{\mathrm{it}+1}} \frac{\partial \mathrm{e}_{\mathrm{it}+1}^{\mathrm{net}}}{\partial \tau_{\mathrm{et}+1}}+ \\
& +(1+\gamma)^{-2} \sum_{\mathrm{i}} \frac{\partial \mathrm{W}}{\partial \mathrm{b}_{\mathrm{it}+1}} \frac{\partial \mathrm{b}_{\mathrm{it}+1}}{\partial \mathrm{x}_{\mathrm{it}+1}} \frac{\partial \mathrm{e}_{\mathrm{it}+1}^{\mathrm{net}}}{\partial \tau_{\mathrm{et}+1}}+\tilde{\lambda}_{\mathrm{t}+1}^{\mathrm{d}} \sum_{\mathrm{i}}\left(\frac{\partial \mathrm{e}_{\mathrm{it}+1}}{\partial \tau_{\mathrm{et}+1}}-\frac{\partial \mathrm{e}_{\mathrm{it}+1}^{\mathrm{net}}}{\partial \tau_{\mathrm{et}+1}}\right)+ \\
& +\tilde{\lambda}_{\mathrm{t}+1}^{\mathrm{d}} \tau_{\mathrm{t}+1} \sum_{\mathrm{i}}\left(\frac{\partial \mathrm{c}_{\mathrm{it}+1}}{\partial \mathrm{x}_{\mathrm{it}+1}}+\frac{\partial \mathrm{b}_{\mathrm{it}+1}}{\partial \mathrm{x}_{\mathrm{it}+1}}\right) \frac{\partial \mathrm{e}_{\mathrm{it}+1}^{\mathrm{net}}}{\partial \tau_{\mathrm{et}+1}}+\tilde{\mu}_{\mathrm{t}}^{\mathrm{d}} \frac{1+\tau_{\mathrm{t}}}{\left(1-\tau_{\mathrm{et}+1}\right)^{2}}\left(-\frac{\partial \mathrm{v}_{\mathrm{t}}^{\mathrm{H}}}{\partial \mathrm{x}_{\mathrm{Ht}}} \mathrm{b}_{\mathrm{Ht}}^{\mathrm{net}}+\right. \\
& \left.+\frac{\partial \mathrm{v}_{\mathrm{t}}^{\mathrm{H}}[\mathrm{L}]}{\partial \mathrm{x}_{\mathrm{Lt}}} \mathrm{b}_{\mathrm{Ht}}^{\mathrm{net}}[\mathrm{L}]\right)+\tilde{\mu}_{\mathrm{t}+1}^{\mathrm{d}}\left(\frac{\partial \mathrm{v}_{\mathrm{t}+1}^{\mathrm{H}}}{\partial \mathrm{x}_{\mathrm{Ht}+1}}-\frac{\partial \mathrm{v}_{\mathrm{t}+1}^{\mathrm{H}}[\mathrm{L}]}{\partial \mathrm{x}_{\mathrm{Lt}+1}}\right) \frac{\partial \mathrm{e}_{\mathrm{Ht}+1}^{\mathrm{net}}}{\partial \tau_{\mathrm{et}+1}}
\end{aligned}
$$

Finally, we derive the first-order conditions from the Lagrangian to the maximization problem (8) and (A13) - (A16) with respect to $\mathrm{x}_{\mathrm{Lt}+1}, \mathrm{x}_{\mathrm{Ht}+1}$ (we use again that $\left.\partial \mathrm{b}_{\mathrm{it}+1} / \partial \mathrm{x}_{\mathrm{it}+1}=\left(\partial \mathrm{b}_{\mathrm{it}+1}^{\text {net }} / \partial \mathrm{x}_{\mathrm{it}+1}\right) /\left(1-\tau_{\mathrm{et}+2}\right)\right)$ :

$$
\begin{array}{r}
(1+\gamma)^{-1} \mathrm{f}_{\mathrm{Lt}+1} \frac{\partial \mathrm{v}_{\mathrm{t}+1}^{\mathrm{L}}}{\partial \mathrm{x}_{\mathrm{Lt}+1}}+(1+\gamma)^{-2} \frac{\partial \mathrm{W}}{\partial \mathrm{b}_{\mathrm{Lt}+1}} \frac{\partial \mathrm{b}_{\mathrm{Lt}+1}}{\partial \mathrm{x}_{\mathrm{Lt}+1}}-\tilde{\lambda}_{\mathrm{t}+1}^{\mathrm{d}}+ \\
+\tilde{\lambda}_{\mathrm{t}+1}^{\mathrm{d}} \tau_{\mathrm{t}+1}\left(\frac{\partial \mathrm{c}_{\mathrm{Lt}+1}}{\partial \mathrm{x}_{\mathrm{Lt}+1}}+\frac{\partial \mathrm{b}_{\mathrm{Lt}+1}}{\partial \mathrm{x}_{\mathrm{Lt}+1}}\right)-\tilde{\mu}_{\mathrm{t}+1}^{\mathrm{d}} \frac{\partial \mathrm{v}_{\mathrm{t}+1}^{\mathrm{H}}[\mathrm{L}]}{\partial \mathrm{x}_{\mathrm{Lt}+1}}=0
\end{array}
$$




$$
\begin{gathered}
(1+\gamma)^{-1} \mathrm{f}_{\mathrm{Ht}+1} \frac{\partial \mathrm{v}_{\mathrm{t}+1}^{\mathrm{H}}}{\partial \mathrm{x}_{\mathrm{Ht}+1}}+(1+\gamma)^{-2} \frac{\partial \mathrm{W}}{\partial \mathrm{b}_{\mathrm{Ht}+1}} \frac{\partial \mathrm{b}_{\mathrm{Ht}+1}}{\partial \mathrm{x}_{\mathrm{Ht}+1}}-\tilde{\lambda}_{\mathrm{t}+1}^{\mathrm{d}}+ \\
+\tilde{\lambda}_{\mathrm{t}+1}^{\mathrm{d}} \tau_{\mathrm{t}+1}\left(\frac{\partial \mathrm{c}_{\mathrm{Ht}+1}}{\partial \mathrm{x}_{\mathrm{Ht}+1}}+\frac{\partial \mathrm{b}_{\mathrm{Ht}+1}}{\partial \mathrm{x}_{\mathrm{Ht}+1}}\right)+\tilde{\mu}_{\mathrm{t}+1}^{\mathrm{d}} \frac{\partial \mathrm{v}_{\mathrm{t}}^{\mathrm{H}}}{\partial \mathrm{x}_{\mathrm{Ht}}}=0 .
\end{gathered}
$$

Multiplying (A20) by $\partial \mathrm{e}_{\mathrm{Lt}+1}^{\text {net }} / \partial \tau_{\mathrm{et+1}}$ and (A21) by $\partial \mathrm{e}_{\mathrm{Ht}+1}^{\text {net }} / \partial \tau_{\mathrm{et}+1}$, resp., and substituting into (A19), gives us the formula of Theorem 3(a).

(b) Follows immediately from the fact that indirect utility $v_{t}^{\mathrm{i}}(\cdot)$ of an individual $\mathrm{i}$ of generation $\mathrm{t}$ - even if she cares for net bequests - does not depend on $\tau_{t+1}$, neither do net bequests $b_{i t}^{\text {net }}(\cdot)$ nor consumption $c_{i t}(\cdot)$.

QED

\section{Proof of Theorem 4}

The first-order conditions for optimal $\mathrm{x}_{\mathrm{Lt}}, \mathrm{x}_{\mathrm{Ht}}$ of the optimization problem (5) - (7), with $\tau_{\mathrm{bt}}$ instead of $\tau_{\mathrm{t}}$, read similar to (A6), (A7):

$$
\begin{aligned}
& \mathrm{f}_{\mathrm{Lt}} \frac{\partial \mathrm{v}_{\mathrm{t}}^{\mathrm{L}}}{\partial \mathrm{x}_{\mathrm{Lt}}}+(1+\gamma)^{-1} \frac{\partial \mathrm{W}}{\partial \mathrm{b}_{\mathrm{Lt}}} \frac{\partial \mathrm{b}_{\mathrm{Lt}}}{\partial \mathrm{x}_{\mathrm{Lt}}}-\lambda^{\mathrm{d}}+\lambda^{\mathrm{d}} \tau_{\mathrm{bt}} \frac{\partial \mathrm{b}_{\mathrm{Lt}}}{\partial \mathrm{x}_{\mathrm{Lt}}}-\mu^{\mathrm{d}} \frac{\partial \mathrm{v}_{\mathrm{t}}^{\mathrm{H}}[\mathrm{L}]}{\partial \mathrm{x}_{\mathrm{Lt}}}=0 \\
& \mathrm{f}_{\mathrm{Ht}} \frac{\partial \mathrm{v}_{\mathrm{t}}^{\mathrm{H}}}{\partial \mathrm{x}_{\mathrm{Ht}}}+(1+\gamma)^{-1} \frac{\partial \mathrm{W}}{\partial \mathrm{b}_{\mathrm{Ht}}} \frac{\partial \mathrm{b}_{\mathrm{Ht}}}{\partial \mathrm{x}_{\mathrm{Ht}}}-\lambda^{\mathrm{d}}+\lambda^{\mathrm{d}} \tau_{\mathrm{bt}} \frac{\partial \mathrm{b}_{\mathrm{Ht}}}{\partial \mathrm{x}_{\mathrm{Ht}}}+\mu^{\mathrm{d}} \frac{\partial \mathrm{v}_{\mathrm{t}}^{\mathrm{H}}}{\partial \mathrm{x}_{\mathrm{Ht}}}=0 .
\end{aligned}
$$

Using $\quad \partial v_{t}^{\mathrm{i}} / \partial \tau_{\mathrm{bt}}=-\mathrm{b}_{\mathrm{it}} \partial \mathrm{v}_{\mathrm{t}}^{\mathrm{i}} / \partial \mathrm{x}_{\mathrm{it}}, \partial \mathrm{v}_{\mathrm{t}}^{\mathrm{H}}[\mathrm{L}] / \partial \tau_{\mathrm{bt}}=-\mathrm{b}_{\mathrm{Ht}}[\mathrm{L}] \partial \mathrm{v}_{\mathrm{t}}^{\mathrm{H}}[\mathrm{L}] / \partial \mathrm{x}_{\mathrm{Lt}}$ and the Slutsky relation $\partial b_{i t} / \partial \tau_{b t}=\partial b_{i t}^{\text {com }} / \partial \tau_{b t}-b_{i t} \partial b_{i t} / \partial x_{i t}$, the welfare effect of $\tau_{b t}$ can be written as

$$
\begin{aligned}
\frac{\partial S^{\mathrm{d}}}{\partial \tau_{\mathrm{bt}}}= & \sum_{\mathrm{i}=\mathrm{L}, \mathrm{H}}\left\{-\mathrm{f}_{\mathrm{it}} \mathrm{b}_{\mathrm{it}} \frac{\partial \mathrm{v}_{\mathrm{t}}^{\mathrm{i}}}{\partial \mathrm{x}_{\mathrm{it}}}+(1+\gamma)^{-1} \frac{\partial \mathrm{W}}{\partial \mathrm{b}_{\mathrm{it}}}\left(\frac{\partial \mathrm{b}_{\mathrm{it}}^{\mathrm{com}}}{\partial \tau_{\mathrm{bt}}}-\mathrm{b}_{\mathrm{it}} \frac{\partial \mathrm{b}_{\mathrm{it}}}{\partial \mathrm{x}_{\mathrm{it}}}\right)+\right. \\
& \left.+\lambda^{\mathrm{d}}\left[\mathrm{b}_{\mathrm{it}}+\tau_{\mathrm{bt}}\left(\frac{\partial \mathrm{b}_{\mathrm{it}}^{\mathrm{com}}}{\partial \tau_{\mathrm{bt}}}-\mathrm{b}_{\mathrm{it}} \frac{\partial \mathrm{b}_{\mathrm{it}}}{\partial \mathrm{x}_{\mathrm{it}}}\right)\right]\right\}+\mu^{\mathrm{d}}\left(-\mathrm{b}_{\mathrm{Ht}} \frac{\partial \mathrm{v}_{\mathrm{t}}^{\mathrm{H}}}{\partial \mathrm{x}_{\mathrm{Ht}}}\right. \\
& +\mathrm{b}_{\mathrm{Ht}}[\mathrm{L}] \frac{\partial \mathrm{v}_{\mathrm{t}}^{\mathrm{H}}[\mathrm{L}]}{\partial \mathrm{x}_{\mathrm{Lt}}}
\end{aligned}
$$

Multiplying (A22) by $b_{\mathrm{Lt}}$ and (A23) by $\mathrm{b}_{\mathrm{Ht}}$ and adding both to (A24) given us the formula of Theorem 4.

QED 


\section{Proof of Theorem 5}

(a) From the Lagrangian to the problem (10), (11'), (12), we derive the first-order conditions for the optimum $x_{i t}, i=1, \ldots, n$, where $\lambda^{r}, \mu_{i}^{r}, i=2, \ldots, n$, are the multipliers corresponding to the resource constraint and the self-selection constraints, respectively (remember that $\partial \mathrm{v} / \partial \mathrm{x}=\rho /\left(1+\tau_{\mathrm{t}}\right), \partial \mathrm{c} / \partial \mathrm{x}=\alpha_{\mathrm{c}} /(1+\tau), \partial \mathrm{b} / \partial \mathrm{x}=\alpha_{\mathrm{b}} /(1+\tau)$ and $\alpha_{\mathrm{c}}+$ $\left.\alpha_{\mathrm{b}}=1\right)$ :

$$
\begin{aligned}
& \frac{\mathrm{f}_{1 \mathrm{t}} \rho}{1+\tau_{\mathrm{t}}}+(1+\gamma)^{-1} \frac{\alpha_{\mathrm{b}}}{1+\tau_{\mathrm{t}}} \sum_{\mathrm{j}=1}^{\mathrm{k}} \frac{\partial \mathrm{W}}{\partial \mathrm{b}_{1 \mathrm{t}}^{\mathrm{j}}} \kappa_{\mathrm{jt}}-\lambda^{\mathrm{r}}+\lambda^{\mathrm{r}} \frac{\tau_{\mathrm{t}}}{1+\tau_{\mathrm{t}}}-\frac{\mu_{2}^{\mathrm{r}} \rho}{1+\tau_{\mathrm{t}}}=0, \\
& \frac{\mathrm{f}_{\mathrm{it}} \rho}{1+\tau_{\mathrm{t}}}+(1+\gamma)^{-1} \frac{\alpha_{\mathrm{b}}}{1+\tau_{\mathrm{t}}} \sum_{j=1}^{\mathrm{k}} \frac{\partial \mathrm{W}}{\partial \mathrm{b}_{\mathrm{it}}^{\mathrm{j}}} \kappa_{\mathrm{jt}}-\lambda^{\mathrm{r}}+\lambda^{\mathrm{r}} \frac{\tau_{\mathrm{t}}}{1+\tau_{\mathrm{t}}}+\frac{\mu_{\mathrm{i}}^{\mathrm{r}} \rho}{1+\tau_{\mathrm{t}}}- \\
& \quad-\frac{\mu_{\mathrm{i}+1}^{\mathrm{r}} \rho}{1+\tau_{\mathrm{t}}}=0, \\
& \frac{\mathrm{f}_{\mathrm{nt}} \rho}{1+\tau_{\mathrm{t}}}+(1+\gamma)^{-1} \frac{\alpha_{\mathrm{b}}}{1+\tau_{\mathrm{t}}} \sum_{\mathrm{j}=1}^{\mathrm{k}} \frac{\partial \mathrm{W}}{\partial \mathrm{b}_{\mathrm{nt}}^{\mathrm{j}}} \kappa_{\mathrm{jt}}-\lambda^{\mathrm{r}}+\lambda^{\mathrm{r}} \frac{\tau_{\mathrm{t}}}{1+\tau_{\mathrm{t}}}+\frac{\mu_{\mathrm{n}}^{\mathrm{r}} \rho}{1+\tau_{\mathrm{t}}}=0 .
\end{aligned}
$$

Next we consider the derivative of the Lagrangian with respect to $\tau_{\mathrm{et}}$ :

$$
\frac{\partial S^{r}}{\partial \tau_{e t}}=\sum_{j=1}^{k} \sum_{i=1}^{n} f_{i t} \frac{\partial v_{t}^{i}}{\partial \tau_{e t}} \kappa_{j t}+(1+\gamma)^{-1} \sum_{j=1}^{k} \sum_{i=1}^{n} \frac{\partial W}{\partial b_{i t}^{j}} \frac{\partial b_{i t}^{j}}{\partial \tau_{e t}} \kappa_{j t}+\lambda^{r} e_{t}^{a g}-\lambda^{r} \frac{\tau_{t}}{1+\tau_{t}} e_{t}^{a g}
$$

Using $\partial v_{t}^{i}\left(\cdot, e_{i t}^{j}, \cdot\right) / \partial \tau_{e t}=-e_{i t}^{j} \partial v_{t}^{i} / \partial x_{i t}=-e_{i t}^{j} \rho /\left(1+\tau_{t}\right) \quad$ and $\quad \partial b_{i t}^{j} / \partial \tau_{e t}=-e_{i t}^{j} \alpha_{b} /\left(1+\tau_{t}\right)$, (A25) reads

$$
\frac{\partial \mathrm{S}^{\mathrm{r}}}{\partial \tau_{\mathrm{et}}}=-\frac{\rho}{1+\tau_{\mathrm{t}}} \sum_{\mathrm{i}=1}^{\mathrm{n}} \mathrm{f}_{\mathrm{it}} \overline{\mathrm{e}}_{\mathrm{it}}-(1+\gamma)^{-1} \frac{\alpha_{\mathrm{b}}}{1+\tau_{\mathrm{t}}} \sum_{\mathrm{i}=1}^{\mathrm{n}} \overline{\mathrm{e}}_{\mathrm{it}} \frac{\partial \mathrm{W}}{\partial \mathrm{b}_{\mathrm{it}}}+\lambda^{\mathrm{r}} \mathrm{e}_{\mathrm{t}}^{\mathrm{ag}}-\lambda^{\mathrm{r}} \frac{\tau_{\mathrm{t}}}{1+\tau_{\mathrm{t}}} \mathrm{e}_{\mathrm{t}}^{\mathrm{ag}}
$$

Here we have used the property that $\partial \mathrm{W} / \partial \mathrm{b}_{\mathrm{it}}^{\mathrm{j}}$ is assumed independent of $\mathrm{j}$, as mentioned in the text (we write $\partial \mathrm{W} / \partial \mathrm{b}_{\mathrm{it}}$ ). Using this property again in (A25) - (A27) and multiplying each equation by the appropriate $\overline{\mathrm{e}}_{\mathrm{it}}$ gives

$$
-\frac{\mathrm{f}_{1 \mathrm{t}} \rho}{1+\tau_{\mathrm{t}}} \overline{\mathrm{e}}_{1 \mathrm{t}}=(1+\gamma)^{-1} \frac{\alpha_{\mathrm{b}}}{1+\tau_{\mathrm{t}}} \overline{\mathrm{e}}_{1 \mathrm{t}} \frac{\partial \mathrm{W}}{\partial \mathrm{b}_{1 \mathrm{t}}}-\lambda^{\mathrm{r}} \overline{\mathrm{e}}_{1 \mathrm{t}}+\lambda^{\mathrm{r}} \frac{\tau_{\mathrm{t}}}{1+\tau_{\mathrm{t}}} \overline{\mathrm{e}}_{1 \mathrm{t}}-\frac{\mu_{2}^{\mathrm{r}} \rho}{1+\tau_{\mathrm{t}}} \overline{\mathrm{e}}_{1 \mathrm{t}},
$$




$$
\begin{aligned}
&-\frac{\mathrm{f}_{\mathrm{it}} \rho}{1+\tau_{\mathrm{t}}} \overline{\mathrm{e}}_{\mathrm{it}}=(1+\gamma)^{-1} \frac{\alpha_{\mathrm{b}}}{1+\tau_{\mathrm{t}}} \overline{\mathrm{e}}_{\mathrm{it}} \frac{\partial \mathrm{W}}{\partial \mathrm{b}_{\mathrm{it}}}-\lambda^{\mathrm{r}} \overline{\mathrm{e}}_{\mathrm{it}}+\lambda^{\mathrm{r}} \frac{\tau_{\mathrm{t}}}{1+\tau_{\mathrm{t}}} \overline{\mathrm{e}}_{\mathrm{it}}+\frac{\mu_{\mathrm{i}}^{\mathrm{r}} \rho}{1+\tau_{\mathrm{t}}} \overline{\mathrm{e}}_{\mathrm{it}}- \\
&-\frac{\mu_{\mathrm{i}+1}^{\mathrm{r}} \rho}{1+\tau_{\mathrm{t}}} \overline{\mathrm{e}}_{\mathrm{it}}, \mathrm{i}=2, \ldots, \mathrm{n}-1, \\
&-\frac{\mathrm{f}_{\mathrm{nt}} \rho}{1+\tau_{\mathrm{t}}} \overline{\mathrm{e}}_{\mathrm{nt}}=(1+\gamma)^{-1} \frac{\alpha_{\mathrm{b}}}{1+\tau_{\mathrm{t}}} \overline{\mathrm{e}}_{\mathrm{nt}} \frac{\partial \mathrm{W}}{\partial \mathrm{b}_{\mathrm{nt}}}-\lambda^{\mathrm{r}} \overline{\mathrm{e}}_{\mathrm{nt}}+\lambda^{\mathrm{r}} \frac{\tau_{\mathrm{t}}}{1+\tau_{\mathrm{t}}} \overline{\mathrm{e}}_{\mathrm{nt}}+\frac{\mu_{\mathrm{n}}^{\mathrm{r}} \rho}{1+\tau_{\mathrm{t}}} \overline{\mathrm{e}}_{\mathrm{nt}} .
\end{aligned}
$$

Substituting (A30) - (A32) into (A29) and observing that, by assumption

$$
\sum_{\mathrm{i}=1}^{\mathrm{n}} \overline{\mathrm{e}}_{\mathrm{it}}=\sum_{\mathrm{i}=1}^{\mathrm{n}} \sum_{\mathrm{j}=1}^{\mathrm{k}} \mathrm{e}_{\mathrm{it}}^{\mathrm{j}} \kappa_{\mathrm{jt}}=\sum_{\mathrm{j}=1}^{\mathrm{k}} \kappa_{\mathrm{j}} \sum_{\mathrm{i}=1}^{\mathrm{n}} \mathrm{e}_{\mathrm{it}}^{\mathrm{j}}=\mathrm{e}_{\mathrm{t}}^{\mathrm{ag}},
$$

gives us the formula of Theorem 4(a).

(b) The proof of Theorem 4(b) is analogous. 


\section{References}

Atkinson, A.B., Stiglitz, J.E., 1976. The design of tax structure: direct versus indirect taxation, Journal of Public Economics 6, 55-75.

Barro, R., 1974. Are Government bonds net wealth? Journal of Political Economy 82, 1095-1117.

Blumkin, T., Sadka, E., 2003. Estate Taxation with intended and accidental bequests. Journal of Public Economics 88, 1-21.

Boadway, R., Marchand, M., Pestieau P., 2000. Redistribution with Unobservable Bequests: A Case for Taxing Capital Income. Scandinavian Journal of Economics 102(2), 253-267.

Brunner, J. K., 1989. Theory of equitable taxation. Berlin et al.: Springer.

Brunner, J. K., Pech, S., 2010a. Optimum taxation of bequests in a model with initial wealth. Working paper 1001, Department of Economics, University of Linz, Austria.

Brunner, J. K., Pech, S., 2010b. Stochastic intergenerational transition of abilities and the intragenerational distribution of wealth, mimeo, 2010.

Brunner, J. K., Eckerstorfer, P., Pech, S., (2010). Optimal Taxes on Wealth and Consumption in the Presence of Tax Evasion. Working paper 1004, Department of Economics, University of Linz, Austria.

Cremer, H., Pestieau, P., Rochet, J.-Ch., 2001. Direct versus Indirect Taxation: The Design of the Tax Structure Revisited. International Economic Review 42, 781-799.

Cremer, H., Pestieau, P., Rochet, J.-Ch., 2003. Capital income taxation when inherited wealth is not observable. Journal of Public Economics 87, 2475-2490.

Cremer, H., Pestieau, P., 2006. Wealth transfer taxation: a survey of the theoretical literature. In: Kolm, S.-Ch., Ythier, J. M. (Eds.). Handbook of Economics of Giving, Altruism and Reciprocity, Vol. 2. Amsterdam: North-Holland, 1107-1134.

Díaz-Giménez, J., Quadrini, V., Ríos-Rull, J.-V., Budriá Rodriguez, S.B., 2002. Updated Facts on U.S. Distributions of Earnings, Income and Wealth, Federal Reserve Bank of Minneapolis Review, Vol. 26, No. 3, 2-35.

Farhi, E., Werning, I., 2008. Progressive Estate Taxation. mimeo. 
Gale, W.G., Slemrod, J., 2001. Overview. In: Gale, W.G., J.R. Hines, Jr., Slemrod, J. (Eds.). Rethinking Estate and Gift Taxation. Washington D.C.: Brookings Institution Press, 1-64.

Guesnerie, R. Seade, J., 1982, Nonlinear Pricing in a Finite Economy. Journal of Public Economics 17, 157-179.

Kaplow, L., 2001. A Framework for Assessing Estate and Gift Taxation. In: Gale, W.G., J.R. Hines, Jr., Slemrod, J. (Eds.). Rethinking Estate and Gift Taxation, Washington D.C.: Brookings Institution Press, 164-204.

Kessler D., Masson, A., 1989. Bequest and Wealth Accumulation: Are Some Pieces of the Puzzle Missing? Journal of Economic Perspectives 3, 141-152.

Mirrlees, J., 1971. An exploration in the theory of optimum income taxation. Review of Economic Studies 38, 175-208.

Seade, J., 1982. On the sign of the optimum marginal income tax. Review of Economic Studies, 49, 637-643. 